\title{
Axonal Degeneration Is Mediated by Necroptosis Activation
}

\author{
Macarena S. Arrázola, ${ }^{1,2}$ @Cristian Saquel, ${ }^{1}$ @Romina J. Catalán, ${ }^{1}$ @Sebastián A. Barrientos, ${ }^{3}$ Diego E. Hernandez, \\ (D) Nicolás W. Martínez, ${ }^{5}$ Alejandra Catenaccio, ${ }^{1,2}$ and ${ }^{D}$ Felipe A. Court ${ }^{1,2}$ \\ ${ }^{1}$ Center for Integrative Biology, Faculty of Sciences, Universidad Mayor de Chile, Santiago, Chile 8580745, ${ }^{2}$ Fondap Center for Geroscience, Brain Health and \\ Metabolism, Santiago, Chile, ${ }^{3}$ Integrative Neurophysiology and Neurotechnology, Experimental Medical Science, Lund University, Lund, Sweden 22100 , \\ ${ }^{4}$ Cold Spring Harbor Laboratory, Cold Spring Harbor, New York 11724, and ${ }^{5}$ Department of Physiology, Faculty of Biology, Universidad Catolica de Chile, \\ Santiago 8331150, Chile
}

Axonal degeneration, which contributes to functional impairment in several disorders of the nervous system, is an important target for neuroprotection. Several individual factors and subcellular events have been implicated in axonal degeneration, but researchers have so far been unable to identify an integrative signaling pathway activating this self-destructive process. Through pharmacological and genetic approaches, we tested whether necroptosis, a regulated cell-death mechanism implicated in the pathogenesis of several neurodegenerative diseases, is involved in axonal degeneration. Pharmacological inhibition of the necroptotic kinase RIPK1 using necrostatin-1 strongly delayed axonal degeneration in the peripheral nervous system and CNS of wild-type mice of either sex and protected in vitro sensory axons from degeneration after mechanical and toxic insults. These effects were also observed after genetic knock-down of $R I P K 3$, a second key regulator of necroptosis, and the downstream effector MLKL (Mixed Lineage Kinase Domain-Like). RIPK1 inhibition prevented mitochondrial fragmentation in vitro and in vivo, a typical feature of necrotic death, and inhibition of mitochondrial fission by Mdivi also resulted in reduced axonal loss in damaged nerves. Furthermore, electrophysiological analysis demonstrated that inhibition of necroptosis delays not only the morphological degeneration of axons, but also the loss of their electrophysiological function after nerve injury. Activation of the necroptotic pathway early during injury-induced axonal degeneration was made evident by increased phosphorylation of the downstream effector MLKL. Our results demonstrate that axonal degeneration proceeds by necroptosis, thus defining a novel mechanistic framework in the axonal degenerative cascade for therapeutic interventions in a wide variety of conditions that lead to neuronal loss and functional impairment.

Key words: axonal degeneration; mitochondrial fragmentation; MLKL; necroptosis; neurodegeneration; RIP kinase

\section{Significance Statement}

We show that axonal degeneration triggered by diverse stimuli is mediated by the activation of the necroptotic programmed cell-death program by a cell-autonomous mechanism. This work represents a critical advance for the field since it identifies a defined degenerative pathway involved in axonal degeneration in both the peripheral nervous system and the CNS, a process that has been proposed as an early event in several neurodegenerative conditions and a major contributor to neuronal death. The identification of necroptosis as a key mechanism for axonal degeneration is an important step toward the development of novel therapeutic strategies for nervous-system disorders, particularly those related to chemotherapy-induced peripheral neuropathies or CNS diseases in which axonal degeneration is a common factor.

\section{Introduction}

Neurons can extend meter-long axons to carry out their physiological functions (Debanne et al., 2011). However, this architec-

\footnotetext{
Received April 16, 2018; revised Feb. 1, 2019; accepted Feb. 14, 2019.

Author contributions: M.S.A. and F.A.C. designed research; M.S.A., C.S., R.J.C., S.A.B., D.E.H., N.W.M., and A.C. performed research; M.S.A., C.S., R.J.C., S.A.B., and D.E.H. analyzed data; M.S.A. wrote the paper.

This work was supported by grants from the Geroscience Center for Brain Health and Metabolism (FONDAP15150012), Fondo Nacional de Desarrollo Científico y Tecnológico (№. 1150766), Millennium Nucleus RC120003, Ring Initiative ACT1109, and Comisión Nacional de Investigación Científica y Tecnológica, Fondecyt de Postdoctorado Project Nㅜ 3180313 . We thank all members of the Court Laboratory for fruitful discussion and Monica Perez for the electron microscopy processing.
}

ture also makes axons highly susceptible to damage. Axonal degeneration is a common and early feature of many neurological disorders, including amyotrophic lateral sclerosis (ALS), Parkinson's disease (PD), and Alzheimer's disease (AD). Axonal degeneration also commonly occurs after traumatic or chemical insults (Coleman, 2005; Benarroch, 2015; Gerdts et al., 2016).

The authors declare no competing financial interests.

Correspondence should be addressed to Felipe A. Court at felipe.court@umayor.cl.

https://doi.org/10.1523/JNEUROSCI.0881-18.2019

Copyright $\odot 2019$ the authors 
The degenerative process of mechanically isolated axons, known as Wallerian degeneration (Waller, 1850), has been broadly used as a model to unveil the cellular and molecular mechanisms of axonal degeneration (Coleman and Freeman, 2010; Conforti et al., 2014). Likewise, chemotherapeutic agents have also been used to model chemotherapy-induced peripheral neuropathies, a serious and common side effect of cancer treatment (Taillibert et al., 2016). Mechanistic studies in transgenic models displaying delayed Wallerian degeneration (Calixto et al., 2012; Osterloh et al., 2012; Di Stefano et al., 2017) have shown evidence of a regulated axonal self-destruction program (Court and Coleman, 2012; J.T. Wang et al., 2012). The expression of the Wld ${ }^{s}$ protein is the most studied model of delayed axonal degeneration (Mack et al., 2001; Adalbert et al., 2005; Hoopfer et al., 2006). Loss-of-function studies have also identified mutants that exhibit Wld ${ }^{\mathrm{s}}$-like protection of severed axons, such as dSarm/ Sarm1 (Osterloh et al., 2012; Essuman et al., 2017) and Axundead (Neukomm et al., 2017), supporting the idea that Wallerian degeneration is indeed an active and regulated process.

Although axonal degeneration is apoptosis-independent (Finn et al., 2000; Whitmore et al., 2003), both axonal degeneration and apoptosis exhibit some related steps, including a latent phase, where cell death can be delayed, and a subsequent execution phase of cellular breakdown (Geden and Deshmukh, 2016). Mitochondrial dysfunction, by activation of the mitochondrial transition pore (mPTP), calcium imbalance, and reactive oxygen species (ROS) increase, are key events for axonal degeneration (Barrientos et al., 2011; Calixto et al., 2012; Villegas et al., 2014). Mitochondrial fragmentation is also present in diseases in which axon degeneration is a prominent feature (Knott et al., 2008; Court and Coleman, 2012). These events connecting mitochondrial dysfunction with axonal degeneration are also shared features of programmed necrotic cell death, currently known as necroptosis.

Necroptosis is characterized by cellular and organelle swelling, plasma membrane rupture, and the release of cellular contents, inducing a proinflammatory response (Vandenabeele et al., 2010; Orozco and Oberst, 2017). Both apoptosis or necroptosis can be triggered upon TNF $\alpha$-receptor activation (Degterev et al., 2005). Normally, TNF $\alpha$ induces apoptosis through caspase- 8 activation, which in turn inhibits necroptosis by RIPK1 and RIPK3 cleavage (Sun and Wang, 2014). Under caspase-8 inhibition, both kinases are phosphorylated, triggering phosphorylation and oligomerization of MLKL (Mixed Lineage Kinase Domain-Like) and membrane permeabilization (Cai et al., 2014; Tummers and Green, 2017). Other necroptotic activators have been recently described, including increased intracellular $\mathrm{Ca}^{2+}$ (Nomura et al., 2014; Wallach et al., 2016) and ROS (Zhang et al., 2017; Yang et al., 2018).

Necroptosis participates in nervous-system pathologies with prominent axonal degeneration, such as multiple sclerosis (Ofengeim et al., 2015), ALS (Re et al., 2014; Ito et al., 2016), PD (Iannielli et al., 2018), AD (Caccamo et al., 2017), and neuroinflammation (Bian et al., 2017; Daniels et al., 2017), among others (Huang et al., 2013; Vieira et al., 2014). This research has established that there are both neuronal-autonomous roles for necroptosis and noncell autonomous mechanisms participating in nervous-system dysfunction (Tonnus and Linkermann, 2017). However, no one has determined whether necroptosis is activated in a specific neuronal compartment, such as the axon.

Here, we demonstrate that pharmacological inhibition and genetic knock-down of central necroptotic players strongly delayed morphological and functional loss of axons in both pe- ripheral nervous system (PNS) and CNS models of Wallerian degeneration. Furthermore, we observed that, after injury, necroptosis is activated early in axons, followed by mitochondrial fragmentation and progressive degeneration of axons. Inhibition of mitochondrial fission delayed axonal degeneration, supporting the idea that mitochondrial fragmentation is a crucial axondegeneration effector after necroptosis activation. Together, our results identify necroptosis as the programmed mechanism for axonal degeneration, revealing novel molecular targets for neuroprotective therapies in which axonal degeneration is a common factor.

\section{Materials and Methods}

Animals. Wild-type (WT) C57BL/6J [International Mouse Strain Resource (IMSR) catalog \#JAX:000664, RRID:IMSR_JAX:000664] adult mice (25 g) of either sex and Sprague Dawley [Mouse Genome Informatics (MGI) catalog \#5651135, RRID:MGI:5651135] pregnant rats were obtained from the animal facilities of Pontificia Universidad Católica de Chile and Universidad Mayor. Thy1-YFP mice (IMSR catalog \#JAX: 003782, RRID:IMSR_JAX:003782), of either sex, were purchased from the Jackson Laboratory and maintained in the Universidad Mayor animal facility. Experiments with animals followed protocols approved by the institutional animal care and use committees and complied with National Institutes of Health guidelines.

Nerve explant cultures. To study axonal degeneration ex vivo, sciatic and optic nerve segments of 10 and $4 \mathrm{~mm}$, respectively, were dissected from adult WT mice $(n=3)$ and cultured in 24-well dishes containing $400 \mu \mathrm{l}$ of Neurobasal medium (Invitrogen, 21103-049), 2\% B27 (Invitrogen, 17504-044), 0.3\% L-glutamine (Invitrogen, 25030-081), and 1\% streptomycin/penicillin. Explants were cultured at $37^{\circ} \mathrm{C}$ and $5 \% \mathrm{CO}_{2}$ over different periods of time and thereafter fixed with $4 \%$ paraformaldehyde in $1 \times$ PBS for $1 \mathrm{~h}$, followed by three $10 \mathrm{~min}$ washes in $1 \times$ PBS.

Sciatic nerve crush. Mice $(n=3)$ were intraperitoneally anesthetized with Avertin ( $0.37 \mathrm{mg} / \mathrm{g}$; Sigma-Aldrich, T48402) and the sciatic nerve was exposed at the midthigh and crushed three times for $5 \mathrm{~s}$ each using Dumont $\# 5$ forceps. The crushed site was marked with graphite powder applied in the forceps, and the wound was closed using surgical clips. The sciatic nerve was intraperitoneally injected with necrostatin-1 (Nec-1; $1.65 \mathrm{mg} / \mathrm{kg}$; Sigma-Aldrich, N9037) or its vehicle (3\% DMSO in PBS) before crushing as described by Catenaccio et al. (2017).

Teased nerve fibers. Sciatic nerve explants, obtained from Thy1-YFP mice $(n=3)$, were removed from culture medium and immersed in a 1.5 $\mathrm{ml}$ tube with $4 \%$ paraformaldehyde in $1 \times$ PBS for $1 \mathrm{~h}$ at room temperature (RT). Then, nerves were washed three times for $10 \mathrm{~min}$ in $1 \times \mathrm{PBS}$ and transferred into a $35 \mathrm{~mm}$ culture dish with $1 \times$ PBS to remove the perineurium. The bundles were separated with acupuncture needles. Each bundle was placed in a drop of $1 \times$ PBS on a slide coated with 3 -aminopropyltriethoxy silane. The fibers were teased and attached to the slides. After the drops dried, the slides were immersed in cold $100 \%$ acetone for $20 \mathrm{~min}$ at $-20^{\circ} \mathrm{C}$ to proceed with the immunofluorescence protocol detailed below.

Dorsal root ganglion cultures. Briefly, embryonic day 16 rat embryos were decapitated, and the limbs and organs were removed. The spinal cord with dorsal root ganglia (DRGs) was dissected and placed in a Petri dish containing cold L-15 medium (Invitrogen, 11415-064). For DRG explants, complete DRGs were cultured in 24-well dishes containing 400 $\mu$ l of Neurobasal medium, 2\% B27, 0.3\% L-glutamine, 1\% streptomycin/ penicillin, $4 \mu \mathrm{m}$ aphidicolin (Sigma-Aldrich, A0781), $7.5 \mu \mathrm{g} / \mathrm{ml}$ 5-fluoro2-deoxyuridine (Sigma-Aldrich, F0503), and $50 \mathrm{ng} / \mathrm{ml}$ nerve growth factor (Invitrogen, 13257-019). The mixture of aphidicolin and fluoro2-deoxyuridine inhibits proliferation of Schwann cells by inhibition of DNA polymerase (Spadari et al., 1985; Wallace and Johnson, 1989), thus constituting a highly pure sensory neuron culture (Heermann et al., 2012). DRGs were cultured for $7-11 \mathrm{~d}$ at $37^{\circ} \mathrm{C}$ in $5 \% \mathrm{CO}_{2}$. Axotomy of DRG explants was made using a micropipette tip to separate all the axons from the somas. Chemical injury was achieved by adding $1 \mu \mathrm{M}$ vinblastine (Sigma-Aldrich, V1377) to the culture medium. 
Western blot. Axons obtained by axotomy from rat DRG explants $(n=$ 3) were homogenized in radioimmunoprecipitation assay buffer with $1 \%$ protease inhibitor mixture (Sigma-Aldrich, P8340) plus phenylmethylsulfonyl fluoride and phosphatase inhibitors $\mathrm{NaVO}_{3}$ and $\mathrm{NaF}$. Proteins were quantified by bicinchoninic acid assay (Thermo Fisher Scientific, 23225). Loading buffer and $40 \mu \mathrm{g}$ of lysate were combined, subjected to $10 \%$ SDS-PAGE electrophoresis, and transferred to polyvinylidene fluoride membranes (Thermo Fisher Scientific, 88518). The following primary antibodies were used at 1:1000 dilution: anti-RIPK3 (Abcam, catalog \#ab16090, RRID:AB_302252), anti p-MLKL (Abcam, catalog \#ab196436, RRID:AB_2687465), and anti-MLKL (Abcam, catalog \#ab172868, RRID:AB_2737025). Secondary antibodies used were goat anti-mouse horseradish peroxidase (HRP; Bio-Rad, catalog \#170-6516, RRID:AB_11125547) and goat anti-rabbit HRP (Bio-Rad, catalog \#1706515, RRID:AB_11125142) at 1:3000. Western blots were revealed by enhanced chemiluminescence in a Chemi-doc Gel Imaging System (BioRad, XRS+). Band analysis was performed using Image Lab (RRID: SCR_014210) and ImageJ (National Institutes of Health, RRID: SCR_003070) software.

Quantitative real-time PCR. The mRNA levels of RIPK3 and MLKL were analyzed in DRG neurons infected with lentivirus containing short hairpin RIPK3 (shRIPK3) or shMLKL before and after axotomy. Neurons were homogenized in Trizol reagent (Invitrogen) for extraction of total RNA based on the manufacturer's protocol. Total RNA was quantitated using a Multiskan Go ultraviolet/visible spectrophotometer (Thermo Fisher Scientific, 1510). Complementary DNA from $1.0 \mu \mathrm{g}$ of total RNA was synthesized using iScriptTM reverse transcription Supermix for RT-Qpcr (Bio-Rad). mRNA levels in each sample were determined by real-time PCR using EvaGreen qPCR dye. The reverse-transcription product was included in the $5 \times$ HOT FIREPOL EvaGreen qPCR Mix Plus (ROX; Solis BioDyne), along with rat RIPK3 and MLKL primers, and the mixture was placed in the StepOnePlus Real-Time PCR System (Thermo Fisher Scientific, Lightcycler System). Thermal cycling parameters were $30 \mathrm{~s}$ at $95^{\circ} \mathrm{C}$, followed by 40 cycles of $5 \mathrm{~s}$ at $95^{\circ} \mathrm{C}, 5 \mathrm{~s}$ at $60^{\circ} \mathrm{C}$, and $30 \mathrm{~s}$ at $72^{\circ} \mathrm{C}$. At the end of the program, melting curve analysis was performed at $72^{\circ} \mathrm{C}$ for $30 \mathrm{~s}$, followed by a cooling step at $37^{\circ} \mathrm{C}$ for $30 \mathrm{~s}$. Each sample was also run with primers for a housekeeping gene. Primer sequences were obtained from the literature (Liu et al., 2016): rat RIPK3 forward primer $5^{\prime}$-CTGTCGCCTGCTAGAGGAAG-3', and reverse primer $5^{\prime}$-TCTGCTAACTTGGCGTGGAG-3'; rat MLKL forward primer $5^{\prime}$-CCCGAGTTGTTGCAGGAGAT-3', and reverse primer $5^{\prime}$ TCTCCAAGATTCC ATCCGCAG-3'; and Gadph forward primer 5' TCCCTCAAGATTGTCAGCAA-3', and reverse primer $5^{\prime}$-AGATCCA CAACGGATACATT-3'. For relative comparison of each gene, we analyzed the $\mathrm{Ct}$ value with the $\Delta \Delta \mathrm{Ct}$ normalizing method.

Immunofluorescence. For immunofluorescence analysis, the nerve explants were fixed by immersion in $4 \%$ paraformaldehyde in $1 \times$ PBS for $1 \mathrm{~h}$, followed by three $10 \mathrm{~min}$ washes in $1 \times \mathrm{PBS}$, sucrose gradient $(5,10$, and $20 \%$ in $1 \times$ PBS), and then embedded in Optimal Cutting Temperature compound (Sakura Tissue Tek, 4583). Cryostat sections from the middle of the explants were cut transversely at $10 \mu \mathrm{m}$ thickness and mounted on Superfrost Plus slides (Thermo Fisher Scientific, J1800AMNZ). Sections were washed in $1 \times$ PBS for $10 \mathrm{~min}$ and then blocked/permeabilized in $0.1 \%$ Triton X-100, $5 \%$ fish skin gelatin (Sigma-Aldrich, G7765) in $1 \times$ PBS for $1 \mathrm{~h}$ at RT. Sections were incubated in primary antibodies in $0.1 \%$ Triton X-100, $1 \%$ fish skin gelatin solution overnight at $4^{\circ} \mathrm{C}$, washed in $1 \times$ PBS $3 \times 10 \mathrm{~min}$, and incubated in secondary antibodies for $2 \mathrm{~h}$ at RT. Sections were washed $3 \times 10 \mathrm{~min}$ in $1 \times$ PBS and mounted in Fluoromount G (Electron Microscopy Sciences, 17984-25). For immunofluorescence analysis, the embryonary DRG explants were fixed in $4 \%$ paraformaldehyde in $1 \times$ PBS for $20 \mathrm{~min}$, followed by three $10 \mathrm{~min}$ washes in $1 \times$ PBS. The following antibodies were used for immunofluorescence analysis: rabbit anti-neurofilament heavy chain (NFH; Sigma-Aldrich, N4142) at 1:5000; chicken anti-neurofilament medium chain (Millipore, catalog \#AB5735, RRID: AB_240806) at 1:2000; anti-acetylated tubulin (Sigma-Aldrich, catalog \#T6793, RRID:AB_477585) at 1:1000, and COX IV (Abcam, catalog \#ab16056, RRID:AB_443304) at 1:1000. We used secondary antibodies conjugated to AlexaFluor dyes at 1:1000 (Jackson ImmunoResearch Laboratories).

Electron microscopy. Nerves were fixed overnight by immersion in $2.5 \%$ glutaraldehyde, $0.01 \%$ picric acid, and $0.1 \mathrm{M}$ cacodylate buffer, $\mathrm{pH}$ 7.4. Nerves were rinsed in the same buffer, immersed in $1 \% \mathrm{OsO}_{4}$ for $1 \mathrm{~h}$, followed by in block incubation with $2 \%$ uranyl acetate for $2 \mathrm{~h}$. Nerves were dehydrated with a graded series of ethanol and propylene oxide, and infiltrated with Epon (Ted Pella). Ultrathin sections from the middle of the explants were contrasted with $1 \%$ uranyl acetate and lead citrate. Grids were examined with a Philips Tecnai 12 electron microscope operated at $80 \mathrm{kV}$. Negative films were developed and scanned.

Axonal degeneration quantification. The number of axons per area of nerve tissue was assessed in confocal images of neurofilament-immunostained explant sections (matched for laser power, photomultiplier tube gain/offset, and postprocessing) using the particle analysis macro of ImageJ. Relative neurite integrity was based on the ratio of the area of fragmented axons to total axonal area (Villegas et al., 2014). Degenerated axon fragments were detected using the particle analyzer algorithm of Image J and the total fragmented axon area versus total axonal area was used to estimate a degeneration index.

Electrophysiology. The viability of sciatic nerve explants was tested by the recording of the compound action potential (CAP). Sciatic nerve explants from mice were desheathed from the perineurium and transferred to a recording chamber filled with HBSS, supplemented with $5 \mathrm{~mm}$ HEPES buffer, pH 7.35 (Alcayaga et al., 1998). The proximal end of each explant was pinned onto a stimulating bipolar tungsten electrode at the bottom of the recording chamber, while the distal end was pinned onto the recording electrode at the top of the chamber and immersed in mineral oil. Stimulating pulses of $50 \mu$ s each were delivered at $1 \mathrm{~s}$ intervals. The maximum fast monophasic $\mathrm{A}$-wave was obtained by increasing the intensity of the pulse. The maximal peak height and area of the CAP was analyzed.

Virion production and lentiviral transduction. Human embryonic kidney 293T cells (ATCC) were transfected into $15 \mathrm{~cm}^{2}$ dishes using the calcium chloride $(1.25 \mathrm{M})$ method. Media was replaced $4 \mathrm{~h}$ after the initial transfection, and $48 \mathrm{~h}$ later lentivirus-enriched media were collected and cleared by slow centrifugation at $1500 \mathrm{rpm}$ for $5 \mathrm{~min}$. Subsequently, the conditioned media was filtered through a $0.45-\mu \mathrm{m}$-pore conic tube filter. The lentiviruses were concentrated using the Lenti-X Concentrator reagent (Clontech), and then stored at $-80^{\circ} \mathrm{C}$. Four plasmids for lentiviral transduction of RIPK3 shRNA were designed by Biosettia using the Rattus norvegicus RIPK3 mRNA sequence [National Center for Biotechnology Information (NCBI) reference sequence NM_139342.1] and cloned in a pLVRNAi vector that coexpresses GFP as reporter gene. The ripk3 shRNA oligo vector used the following sequences: GAAAGGCTTCTA AAGCAA; GAAGCATCATTTGGGCAT; GAAGAAACAGCAATCCTT; CCTACAGTCTATTGTCTT. One plasmid for lentiviral transduction of MLKL shRNA was designed and packaged by Vigene Bioscience using the Rattus norvegicus MLKL mRNA sequence (NCBI reference sequence XM_008772571.2) and cloned in a pLV-RNAi vector that coexpresses GFP as a reporter gene. The $m l k l$ shRNA oligo vector used the following sequences: GACCAAACTGAAGACAAATAA; TCCCAACATCCTGCG TATATT. One plasmid for lentiviral transduction of scramble shRNA was designed by Vigene Bioscience and cloned in a pLV-RNAi vector that coexpresses GFP as reporter gene. Transduction of DRG explants was performed in $300 \mu \mathrm{l}$ of free-serum media with $1 \times 10^{6} \mathrm{TU}$ (transduction units) per explant in 24-well plates at $2 \mathrm{~d}$ in vitro (DIV) and maintained in culture until axotomy or vinblastine treatment at 7 DIV.

Statistical analysis. Statistical significance was stablished at $p<0.05$ by one-way ANOVA with Tukey's post-test or two-way ANOVA for multiple comparisons. The analysis was performed using GraphPad Prism Software v6.0 and performed with data obtained from $\geq 3$ independent experiments.

\section{Results \\ RIPK1 inhibition delays axonal degeneration in both the PNS and CNS}

To determine whether necroptosis is associated with axonal degeneration, we first used an ex vivo sciatic nerve model of injury- 
A

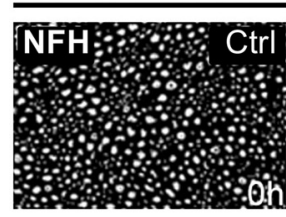

Sciatic nerve

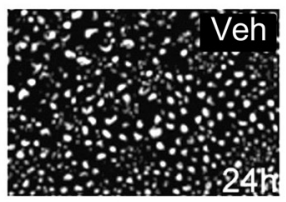

Nec-

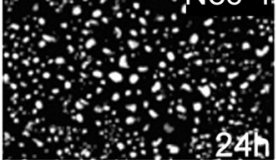

C
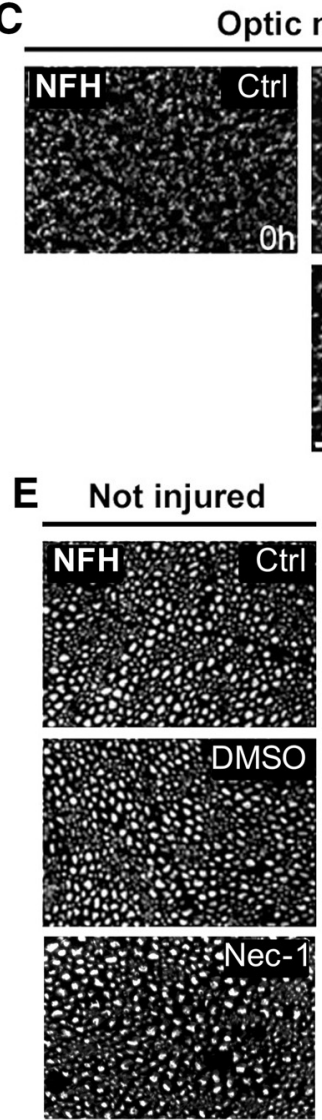

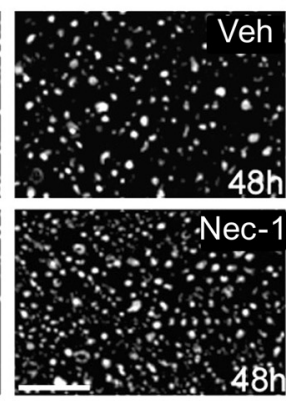

B $^{7}$
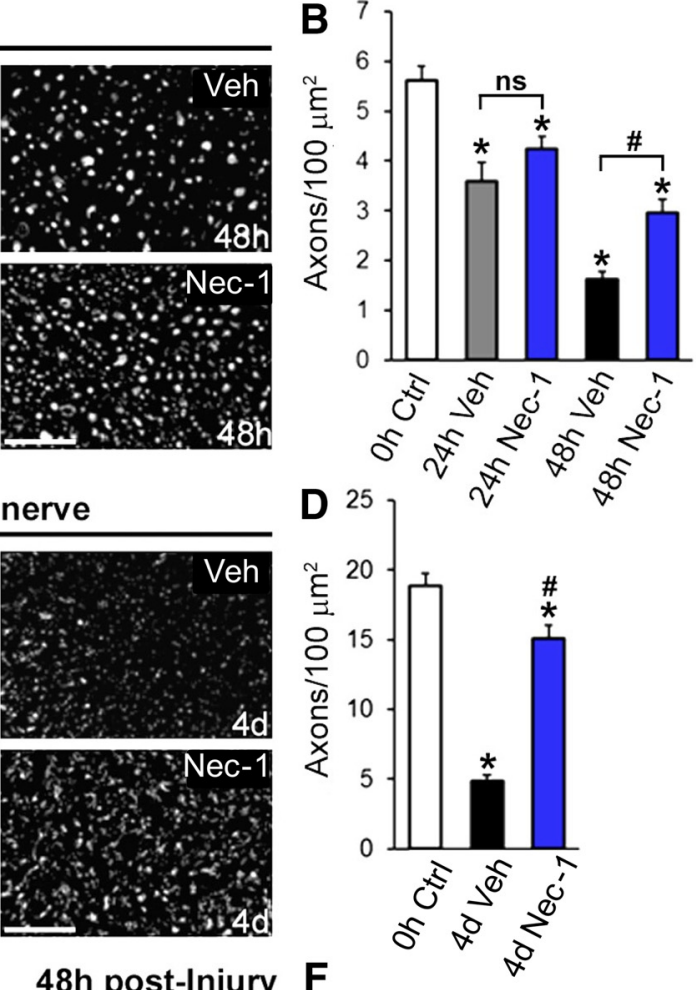
48h post-Injury $F$
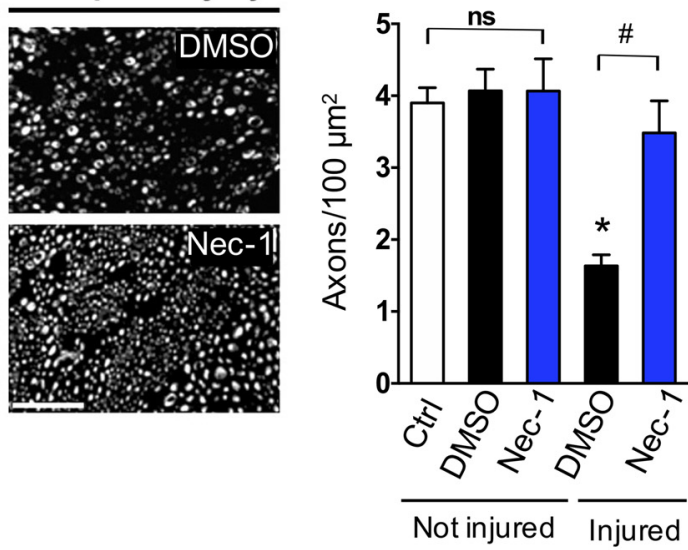

Figure 1. Pharmacological inhibition of RIPK1 delays degeneration of both peripheral and central axons. The degree of axonal degeneration was quantitatively assessed by immunofluorescence using NFH immunostaining in transverse nerve sections. $\boldsymbol{A}-\boldsymbol{D}$, Sciatic and optic nerve explants were treated with Nec-1 (100 $\mu \mathrm{M})$ or vehicle (DMSO) for $48 \mathrm{~h}$ and $4 \mathrm{~d}$, respectively. $\boldsymbol{E}$, Axonal degeneration was evaluated in vivo in crushed sciatic nerves injected with $200 \mu \mathrm{l}$ of $0.64 \mathrm{~mm}$ Nec-1 or vehicle (3\% DMSO in PBS) $48 \mathrm{~h}$ after injury. Nec- 1 treatments strongly delay axonal degeneration triggered by nerve injury. Scale bar, $20 \mu \mathrm{m} . \boldsymbol{B}, \boldsymbol{D}, \boldsymbol{F}$, Quantification of NFH-positive axons in nerve cross sections was expressed as axonal density for both ex vivo explants $(\boldsymbol{B}, \boldsymbol{D})$ and in vivo crushed nerve $(\boldsymbol{F})$. In injured nerves, statistically significant protection from axonal degeneration was seen after Nec-1 treatment compared with vehicle-treated nerves $(\# p<0.0001)$ or noninjured controls $\left({ }^{*} p<0.0001\right)$. Mean values are shown, error bars indicate SEM, $N=3$ per group; analysis was performed by one-way ANOVA test.

induced axonal degeneration. This model allowed us to study axonal degeneration in the absence of any effects from the neuronal cell body or the immune system (Barrientos et al., 2011). We tested the effect of Nec-1, a drug that inhibits the kinase activity of RIPK1 and prevents RIPK1/RIPK3 complex formation, thus strongly inhibiting cell death by necroptosis (Degterev et al., 2008). In vehicle-treated explants, $>50 \%$ of axons degenerated by $48 \mathrm{~h}$ [ $0 \mathrm{~h}$ control (Ctrl): $5.612 \pm 0.29$ axons $/ 100 \mu \mathrm{m}^{2}$; $48 \mathrm{~h}$ vehicle (veh): $1.625 \pm 0.26$ axons $/ 100 \mu \mathrm{m}^{2}, F_{(10,22)}=94.65$, $p<0.0001$, ANOVA], as observed by NFH immunostaining and quantitative analysis of axonal density (Fig. $1 A, B$ ). In explants treated with Nec-1 $(100 \mu \mathrm{M})$, significant protection from axonal degeneration was observed at $48 \mathrm{~h}$ ( $48 \mathrm{~h}$ veh: $1.625 \pm 0.26$ axons/

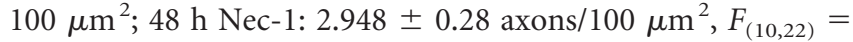
94.65, $p=0.0094$, ANOVA; Fig. $1 A, B)$. To determine the protective effect of Nec-1 in damaged CNS axons, we analyzed optic-nerve explants using the same approach described above. Vehicle-treated optic-nerve explants showed a dramatic reduction in axonal density after $4 \mathrm{~d}$ in culture $(0 \mathrm{~h}$ Ctrl: $18.84 \pm 0.80$ axons $/ 100 \mu \mathrm{m}^{2}$; $4 \mathrm{~d}$ veh: $4.86 \pm 0.41$ axons $/ 100 \mu \mathrm{m}^{2}, F_{(2,18)}=$ 96.97, $p<0.0001$, ANOVA), which was strongly inhibited by Nec-1 $(100 \mu \mathrm{M})$ treatment ( $4 \mathrm{~d}$ veh: $4.86 \pm 0.41$ axons $/ 100 \mu \mathrm{m}^{2}$; $4 \mathrm{~d} \mathrm{Nec}-1: 15.07 \pm 0.89$ axons $/ 100 \mu \mathrm{m}^{2}, F_{(2,18)}=96.97, p<$ 0.0001 , ANOVA; Fig. $1 C, D)$. To test whether RIPK1 inhibition protects degenerating axons in vivo, we injected $2 \mu \mathrm{l}$ of $0.64 \mathrm{~mm}$ of Nec-1 or its vehicle (3\% DMSO in PBS) locally in mouse sciatic 


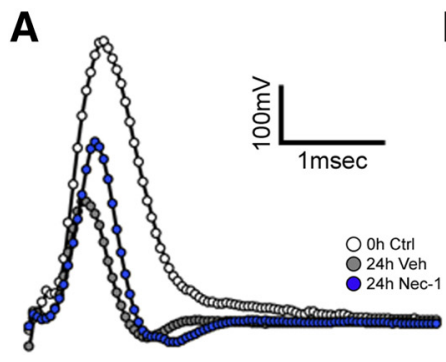

A-wave recording
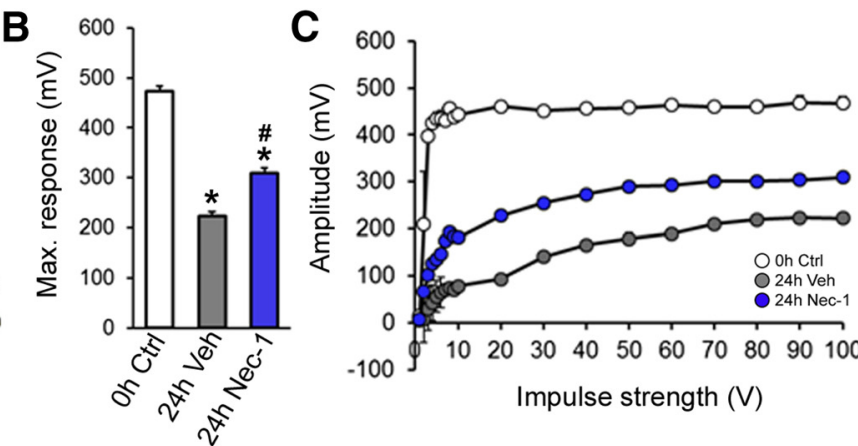

Figure 2. Nerve function is protected by RIPK1 inhibition. The size of the CAP was measured in sciatic nerve explants cultured for $24 \mathrm{~h}$ in the presence or absence of Nec-1 (100 $\mu \mathrm{M}$ ). $\boldsymbol{A}$, CAP A-wave length and amplitude were registered in vehicle-treated nerves. $\boldsymbol{B}$, The maximum peak of the CAP was analyzed. $\boldsymbol{C}$, The recruitment of excitable fibers within the nerve was measured at fixed stimulus intensity and the maximum fast monophasic A-wave was obtained by increasing the intensity of the pulse. Nerves cultured for $24 \mathrm{~h}$ with Nec-1 showed a significantly higher response than nerves cultured under vehicle conditions. One-way ANOVA with post hoc Tukey; \# indicates statistically significant compared with Veh; * indicates statistically significant compared with Ctrl.

nerves. Injected nerves were then crushed proximal to the injection site, and axon density in the distal stump was evaluated $48 \mathrm{~h}$ after injury by NFH immunostaining. We detected a significant decrease in axonal density in injured nerves treated with vehicle compared with undamaged nerves (Ctrl: $4.04 \pm 0.11$ axons/100 $\mu \mathrm{m}^{2}$; injured: $1.63 \pm 0.15$ axons $/ 100 \mu \mathrm{m}^{2}, F_{(3,20)}=16.12, p<$ 0.0001 , ANOVA). Meanwhile, Nec-1 effectively protected axons from degeneration after injury (injured: $1.63 \pm 0.15$ axons/100 $\mu \mathrm{m}^{2}$; injured+Nec-1: $3.48 \pm 0.44$ axons $/ 100 \mu \mathrm{m}^{2}, F_{(3,20)}=$ $16.12, p<0.0001$, ANOVA; Fig. $1 E, F)$. No significant effect was observed for Nec-1 in noninjured axons compared with control conditions. These results suggest that RIPK1 is required for the progression of axonal degeneration in ex vivo and in vivo models of Wallerian degeneration of both the CNS and PNS.

\section{RIPK1 inhibition preserves nerve function during Wallerian degeneration}

Isolated axons progressively lost their capacity to conduct action potentials (Donaldson et al., 2002). To evaluate whether necroptosis inhibition preserves axonal function during Wallerian degeneration, we analyzed the CAP of sciatic nerve explants cultured for $24 \mathrm{~h}$ in the presence or absence of Nec-1 (100 $\mu \mathrm{M})$. At $24 \mathrm{~h}$ after injury, the CAP A-wave of vehicle-treated nerves was severely affected, shortening both length and amplitude to half the A-wave of intact nerves ( $0 \mathrm{~h} \mathrm{Ctrl:} 473.6 \pm 05.67 \mathrm{mV} ; 24 \mathrm{~h}$ veh: $223.3 \pm 4.74 \mathrm{mV}, F_{(2,6)}=557.4, p<0.0001$, ANOVA; Fig. $\left.2 A\right)$. In Nec-1-treated nerves, a significant inhibition of the injuryinduced A-wave amplitude decay was observed compared with damaged and vehicle-treated nerves ( $24 \mathrm{~h}$ veh: $223.3 \pm 4.74 \mathrm{mV}$; $24 \mathrm{~h} \mathrm{Nec}-1: 309.6 \pm 5.69 \mathrm{mV}, F_{(2,6)}=557.4, p<0.0001$, ANOVA; Fig. $2 A, B)$. We also evaluated the recruitment of excitable fibers within the nerve at a fixed stimulus intensity. Myelinated A-fibers of freshly dissected sciatic nerves reached their maximum response at low stimulus intensities. In contrast, nerve explants cultured for $24 \mathrm{~h}$ showed a smaller maximum response, which was only detected under high stimulus intensities, reflecting a lower number of functional axons due to the degenerative process. On the other hand, nerves cultured for $24 \mathrm{~h}$ with $\mathrm{Nec}-1$ showed a significantly higher response than nerves cultured under vehicle conditions. Results were similar at lower stimulus intensities (Fig. 2C). Altogether, these results demonstrate that RIPK1 inhibition, besides protecting axons from morphological degeneration after transection, also preserves some of their ability to function after nerve damage.
Mitochondrial fragmentation and Drp1 activity are crucial for late phases of axonal degeneration

Axonal degeneration after mechanical damage is associated with mitochondrial dysfunction, including a decline in mitochondrial membrane potential and opening of the MPTP (Barrientos et al., 2011). Mitochondrial fragmentation has also been documented as a consequence of necroptosis activation (Young et al., 2010; Z. Wang et al., 2012; Yamada et al., 2016). Therefore, we evaluated changes in mitochondrial morphology during axonal degeneration and the effect of pharmacological RIPK1 inhibition. In uninjured nerves, axonal mitochondria exhibited long, tubular shapes, which become rounded by $48 \mathrm{~h}$ after injury as axons progressively degenerate (Fig. $3 A, B$ ). Using confocal microscopy, we measured mitochondrial length in axons from teased fibers of sciatic nerves at 0,24 , and $48 \mathrm{~h}$ after injury. In intact axons, mitochondria displayed a wide range of lengths from $<2$ $\mu \mathrm{m}$ up to $>8 \mu \mathrm{m}$. At 24 and $48 \mathrm{~h}$ after injury, the distribution of mitochondrial lengths became much narrower and shifted to smaller values (Fig. $3 C$ ), with significant decreases in the mean mitochondrial length $(0 \mathrm{~h}$ Ctrl: $4.116 \pm 0.178 \mu \mathrm{m} ; 24 \mathrm{~h}$ veh: $1.737 \pm 0.123 \mu \mathrm{m} ; 48$ h veh: $0.8024 \pm 0.064 \mu \mathrm{m}, F_{(2,6)}=171.9$, $p<0.0001$, ANOVA; Fig. 3D). Furthermore, a significant increase in mitochondrial density at 24 and $48 \mathrm{~h}$ after injury $(0 \mathrm{~h}$ Ctrl: $22.05 \pm 1.392$ mitochondria/100 $\mu \mathrm{m}^{2} ; 24$ h veh: $34.64 \pm$ 1.734 mitochondria/100 ${\mu \mathrm{m}^{2}}^{2} ; 48 \mathrm{~h}$ veh: $36.21 \pm 1.007$ mitochondria/100 $\mu \mathrm{m}^{2}, F_{(2,51)}=30.33, p<0.0001$, ANOVA; Fig. $3 E$ ) suggests that the changes in mitochondrial length after axonal damage are associated with a fragmentation process. By electron microscopy of longitudinal sections of sciatic nerves, evidence for mitochondrial fragmentation and swelling was commonly observed at 24 and 48 h postinjury, respectively (Fig. $3 F$ ).

We next tested whether axonal mitochondrial fragmentation after nerve injury was associated with RIPK1 activation. To this end, the effect of Nec-1 on injury-induced mitochondrial fragmentation was evaluated. At $24 \mathrm{~h}$ after injury, mitochondrion shortening was inhibited in nerves treated with Nec-1 compared with nerve explants treated with vehicle ( $24 \mathrm{~h}$ veh: $1.351 \pm 0.046$ $\mu \mathrm{m} ; 24 \mathrm{~h} \mathrm{Nec}-1: 2.698 \pm 0.072 \mu \mathrm{m}, F_{(2,1269)}=115.0, p<0.0001$, ANOVA; Fig. $4 A, B)$. In addition, the increase in mitochondrial density $24 \mathrm{~h}$ after damage was inhibited by Nec- 1 when compared with vehicle-treated nerves $(24 \mathrm{~h}$ veh: $33.35 \pm 2.68 \mu \mathrm{m} ; 24 \mathrm{~h}$ Nec-1: $27.87 \pm 1.62 \mu \mathrm{m}, F_{(4,40)}=4.354, p<0.0001$, ANOVA; Fig. 4C). 
A

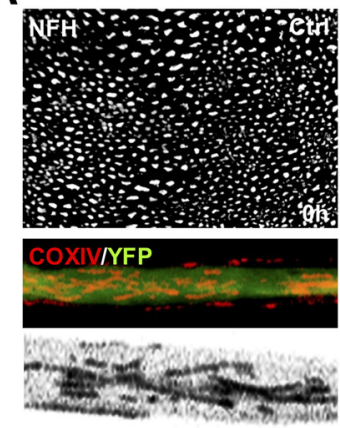

C

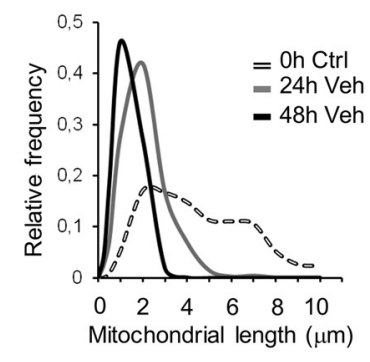

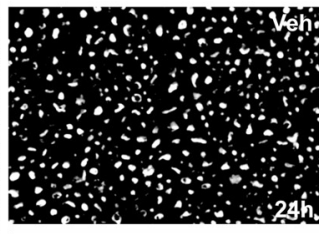

2.

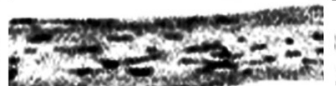

\section{西}

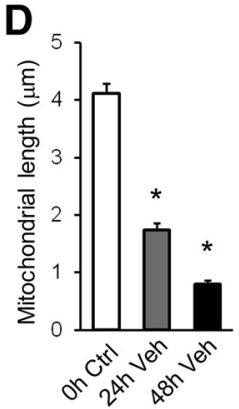

E
B

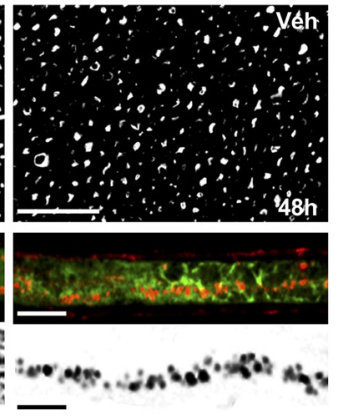

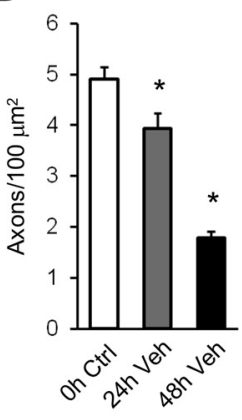
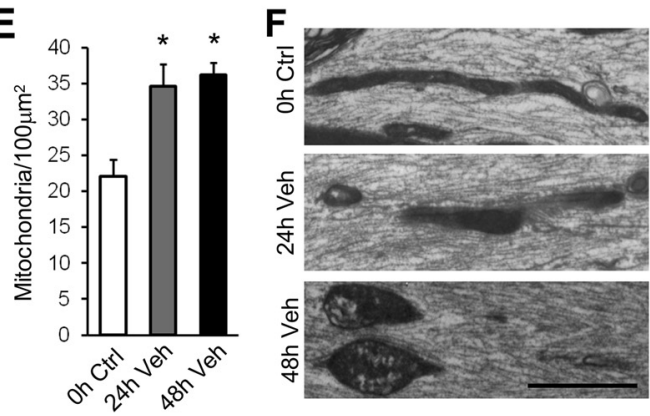

Figure 3. Mitochondrial fragmentation is associated with axonal degeneration after nerve injury. Mitochondrial morphology was evaluated along with axonal degeneration in teased fibers of sciatic nerve explants at 0,24 , and $48 \mathrm{~h}$ after injury. $\boldsymbol{A}, \boldsymbol{B}$, Axonal degeneration progression is shown in nerve transverse sections immunostained for neurofilament $(\boldsymbol{A})$ and quantified as axonal density from NFH-positive axons per area $(\boldsymbol{B})$. Scale bar, $20 \mu \mathrm{m}$. Mitochondria were immunodetected with a COX IV antibody (mitochondria, red) in teased sciatic nerves dissected from Thy1-YFP mice (axons, green). Morphological analysis of mitochondria was performed from COX IV + labeling of binarized images ( $\boldsymbol{A}$, bottom). $\mathrm{Scale}$ bar, $5 \mu \mathrm{m}$. $\boldsymbol{C}, \boldsymbol{D}$, Mitochondrial length was plotted as relative frequency $(\boldsymbol{C})$ and as mean values $(\boldsymbol{D})$. $\boldsymbol{E}$, Decreased mitochondrial length along axonal degeneration was associated with increased mitochondrial density, measured as number of mitochondria per area. $\boldsymbol{F}$, Longitudinal sections of sciatic nerves were analyzed by electron microscopy, showing mitochondrial fragmentation and swelling at 24 and $48 \mathrm{~h}$ after injury, respectively. Scale bar, $1 \mu \mathrm{m}$. One-way ANOVA with post hoc Tukey, ${ }^{*}$ indicates statistically significant compared with Ctrl.

A

coxiv
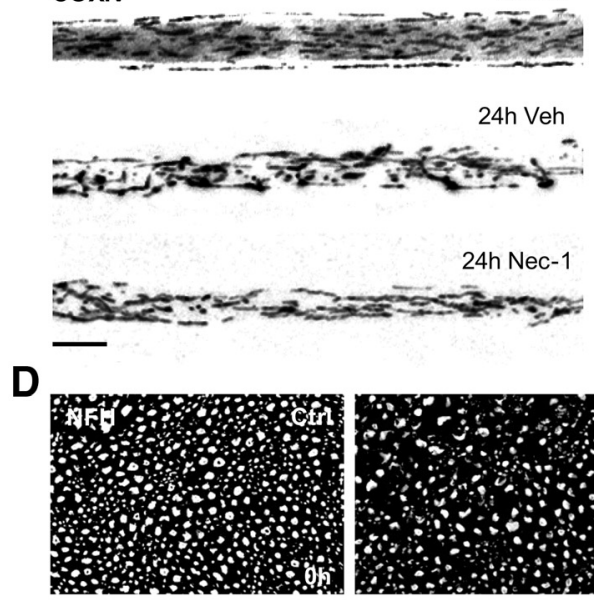

$24 \mathrm{~h} \mathrm{Nec-1}$

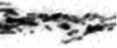
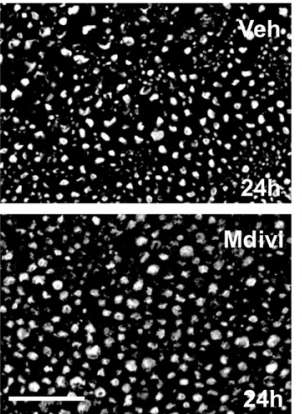

B
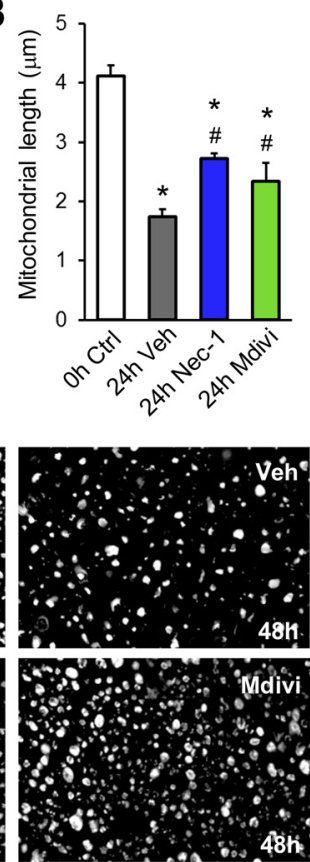

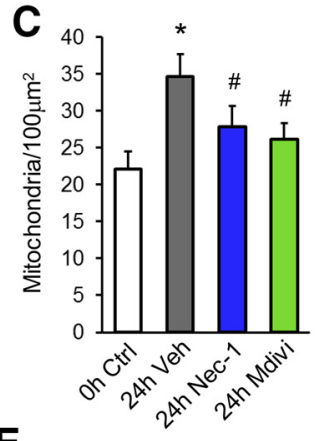

$E$

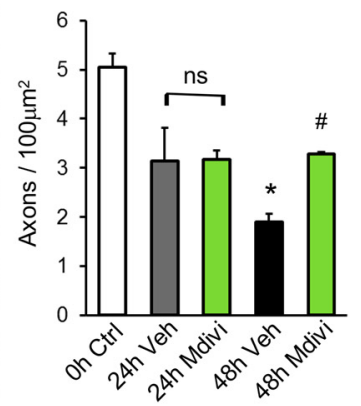

Figure 4. RIPK1 inhibition prevents axonal degeneration-associated mitochondrial fragmentation. $A$, Mitochondrial fragmentation was evaluated at $24 \mathrm{~h}$ after injury from binarized images of COX IV-immunostained teased nerves. $\boldsymbol{B}$, Mitochondrion shortening was inhibited in nerves treated with Nec-1 (100 $\mu \mathrm{M})$ or Mdivi (200 $\mu \mathrm{M})$ compared with nerve explants treated with vehicle. $\boldsymbol{C}$, Increased mitochondrial density was also inhibited by both treatments. $\boldsymbol{D}, \boldsymbol{E}$, Axonal integrity after Mdivi treatment was also evaluated by NFH staining of transversal nerve sections at 24 and $48 \mathrm{~h}$ after injury. One-way ANOVA with post hoc Tukey, ${ }^{*}$ indicates statistically significant compared with Ctrl; \# indicates statistically significant compared with Veh. 

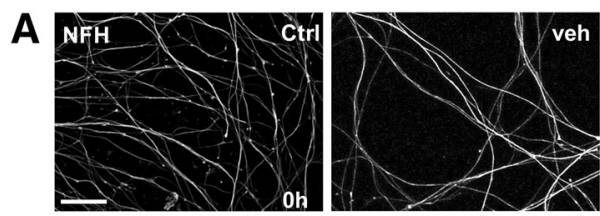

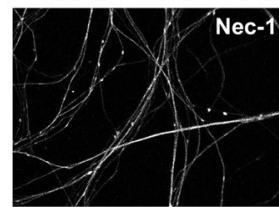

Axotomy

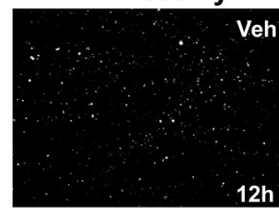

.
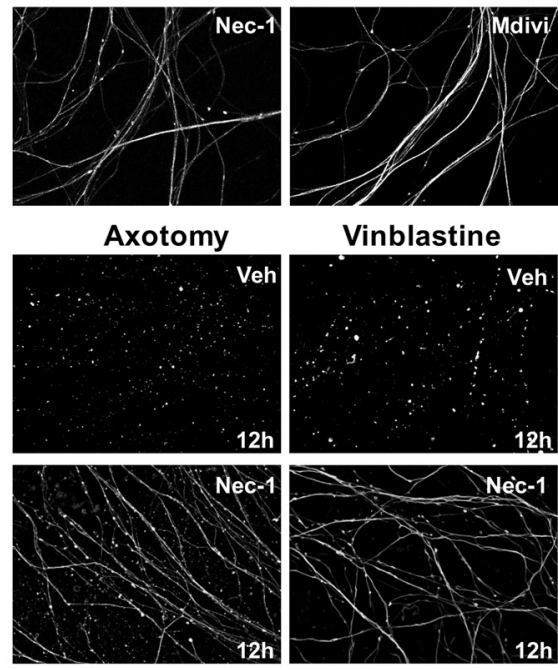

Vinblastine
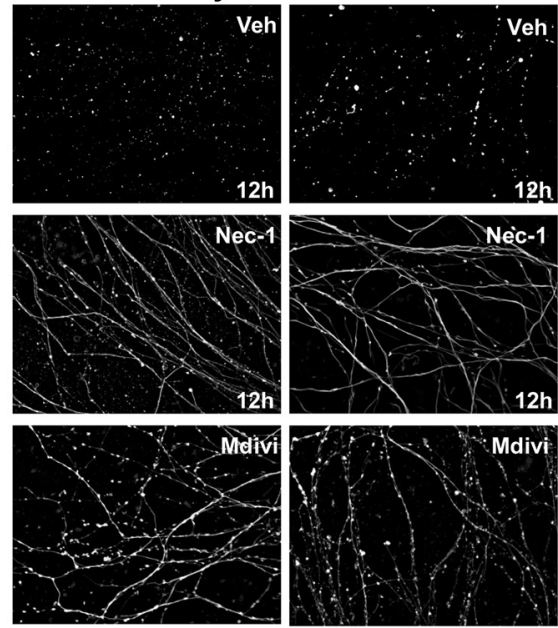

B
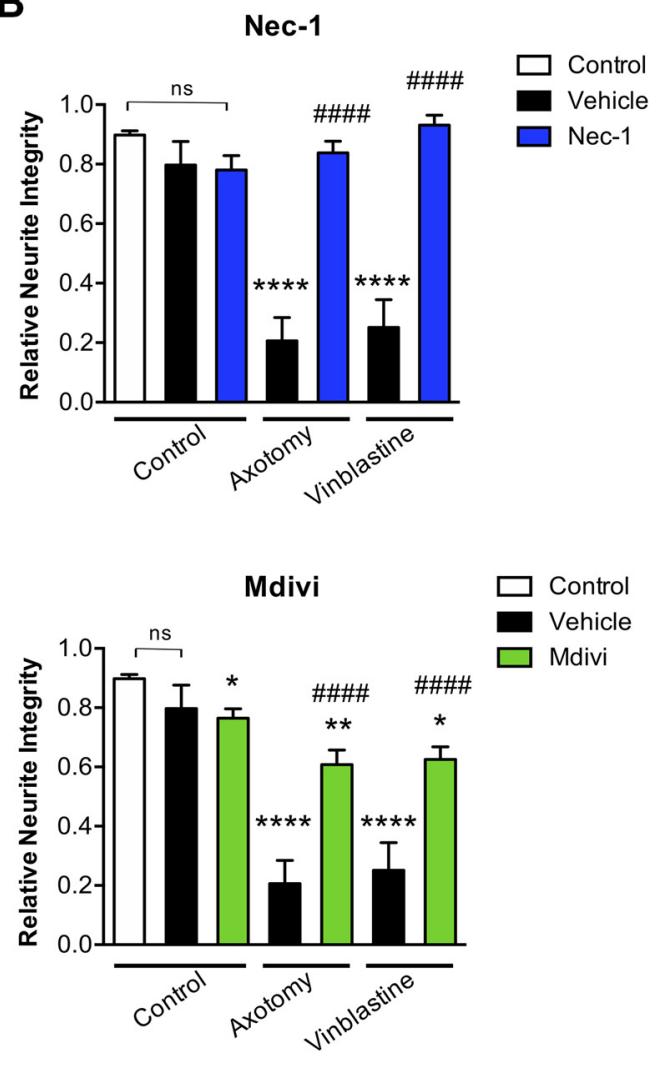

Figure 5. RIPK1 activation and mitochondrial fragmentation contributes to axonal degeneration by a cell-autonomous mechanism. DRG explants were damaged by axotomy or vinblastine $(1 \mu \mathrm{m})$ treatment in the presence of Nec-1, Mdivi, or vehicle as a control, and analyzed after $12 \mathrm{~h} . \boldsymbol{A}, \boldsymbol{B}$, Degeneration was evaluated in distal axons immunostained for NFH ( $\boldsymbol{A}$ ), quantitatively assessed, and represented as relative neurite integrity $(\boldsymbol{B})$. Scale bar, $30 \mu \mathrm{m}$. Two-way ANOVA with post hoc Tukey, ${ }^{*}$ indicates statistically significant compared with Ctrl; \# indicates statistically significant compared with Veh.

Drp1-dependent mitochondrial fragmentation has been associated with the execution stages of necroptosis in cultured cell lines after treatment with TNF- $\alpha$ (Wang Z et al., 2012). To test the contribution of mitochondrial fragmentation to axonal degeneration, sciatic nerve explants were cultured in the presence or absence of Mdivi, a specific pharmacological inhibitor of Drp1 (Cassidy-Stone et al., 2008). Treatment with Mdivi (200 $\mu \mathrm{M}$ ) partially inhibited mitochondrial fragmentation and the increase in mitochondrial density at $24 \mathrm{~h}$ after injury compared with vehicle-treated nerve explants (Fig. $4 B, C$ ). The inhibitory effects of Mdivi in these mitochondrial parameters were comparable to those of nerve explants treated with $\mathrm{Nec}-1$. When axonal integrity after Mdivi treatment was evaluated by NFH immunostaining, a significant inhibition of axonal degeneration was observed $48 \mathrm{~h}$ after injury compared with control nerves ( $48 \mathrm{~h}$ veh: $19.98 \pm 1.31$ axons/100 $\mu \mathrm{m}^{2}$; $48 \mathrm{~h}$ Mdivi: $34.24 \pm 0.86$ axons $/ 100 \mu \mathrm{m}^{2}, F_{(2,9)}$ $=50.4, p=0.0029$, ANOVA; Fig. $4 D, E)$. Cotreatment with Mdivi plus Nec-1 had no additive protective effects, suggesting that Drp-1-dependent mitochondrial fragmentation and RIPK1 activation uses the same signaling pathway to regulate axonal degeneration.

RIPK1 activation and mitochondrial fragmentation contributes to axonal degeneration in a cell-autonomous manner

During Wallerian degeneration, Schwann and immune cells contribute to axonal degeneration (Catenaccio et al., 2017). To analyze whether necroptosis and mitochondrial fragmentation are involved in axonal degeneration in a cell-autonomous manner, pharmacological treatments with $\mathrm{Nec}-1$ and Mdivi were performed in cultures of sensory neurons from DRGs devoid of glial cells (Villegas et al., 2014). Even though embryonic DRG neurons in vitro show very different timing of degeneration compared with sciatic nerve explants (Barrientos et al., 2011), they have been widely used as a model for Wallerian degeneration, since both embryonic DRG neurons and adult sciatic nerves degenerate by a mechanism that depends on Wld ${ }^{\text {s }}$ and Sarm1 (M.S. Wang et al., 2001; Osterloh et al., 2012). Axonal degeneration was induced by either DRG axotomy or treatment with vinblastine ( 1 $\mu \mathrm{M})$, a chemotherapeutic agent that induces Wallerian-like degeneration in peripheral nerves (Bradley et al., 1970; Taillibert et al., 2016) in the presence of Nec-1, Mdivi, or vehicle as a control, and analyzed after $12 \mathrm{~h}$. Axons were immunostained for NFH and axonal integrity was quantitatively assessed. After either axotomy or vinblastine treatment, axons completely degenerate by $12 \mathrm{~h}$ (0 h Ctrl: $0.898 \pm 0.014$ integrity index; $12 \mathrm{~h}$ veh+axotomy: $0.206 \pm 0.079$ integrity index; $12 \mathrm{~h}$ veh + vinblastine: $0.2515 \pm$ 0.093 integrity index, $F_{(6,44)}=33.74, p<0.0001$, two-way ANOVA; Fig. $5 A, B)$. By contrast, Nec-1 treatment completely inhibits axonal degeneration $12 \mathrm{~h}$ after axotomy or vinblastine treatment compared with vehicle-treated axons (axotomy: $12 \mathrm{~h}$ veh: $0.206 \pm 0.079$ integrity index; $12 \mathrm{~h} \mathrm{Nec-1:} 0.838 \pm 0.039$ integrity index; vinblastine: $12 \mathrm{~h}$ veh: $0.2515 \pm 0.093$ integrity index; $12 \mathrm{~h} \mathrm{Nec-1:} 0.931 \pm 0.034$ integrity index; $F_{(6,44)}=33.74$, $p<0.0001$, two-way ANOVA; Fig. $5 A, B)$. No significant effect on axonal degeneration was observed in control axons treated 

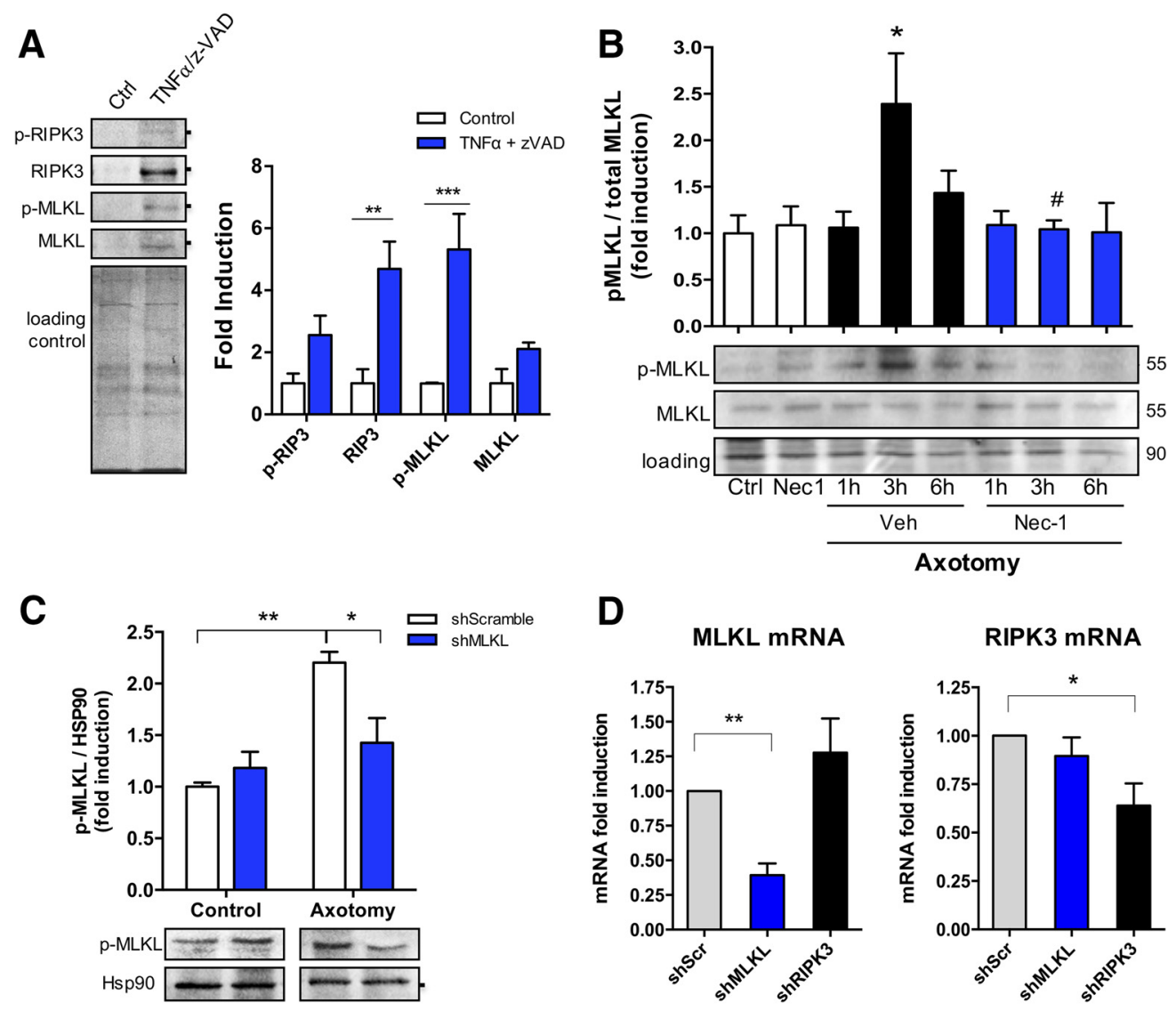

Figure 6. Necroptosis is activated after axonal injury. Necroptotic pathway activation was evaluated after TNF $\alpha / z$-VAD treatment through the detection of RIPK3, MLKL, and their phosphorylated forms by Western blot. $A$, Total protein (Coomassie staining) was used as a loading control to normalize the expression of the different proteins, which were expressed as fold induction compared with control $(n=3)$. Downstream activation of the pathway was determined in mechanically injured axons in a time course $(\leq 6 \mathrm{~h})$ through the detection of MLKL and p-MLKL. Results are represented as pMLKL/MLKL ratio from $n=5$ independent experiments. Total protein was used as a loading control. Two-way ANOVA with post hoc Tukey, ${ }^{*}$ indicates statistically significant compared with Ctrl; \# indicates statistically significant compared with $3 \mathrm{~h}+$ Veh. $\boldsymbol{B}$, C, Specificity of p-MLKL antibody was tested in injured axons devoid of MLKL by using DRGs transduced with lentiviral vectors containing MLKL shRNA $(\boldsymbol{B})$ and compared with a control nontargeting shRNA (scramble; $n=3 ; \boldsymbol{C}$. $\boldsymbol{D}$, The magnitude of MLKL or RIPK3 knock-down was evaluated by real-time qPCR in dissociated DRGs transduced with lentivirus containing shMLKL or shRIPK3, respectively $(n=3)$. One-way ANOVA with post hoc Tukey, ${ }^{*}$ indicates significant compared with Scramble ShRNA.

with Nec-1. Treatment of mechanically or chemically injured axons with Mdivi partially inhibits their degeneration and confers significant protection when compared with vehicle-treated axons (axotomy: $12 \mathrm{~h}$ veh: $0.206 \pm 0.079$ integrity index; $12 \mathrm{~h}$ Mdivi: $0.608 \pm 0.049$ integrity index; vinblastine: $12 \mathrm{~h}$ veh: $0.2515 \pm 0.093$ integrity index; $12 \mathrm{~h}$ Mdivi: $0.625 \pm 0.043$ integrity index; $F_{(6,44)}=33.74, p<0.0001$, two-way ANOVA; Fig. $5 A, B)$. Indeed, treatment of uninjured axons with Mdivi for $\leq 12 \mathrm{~h}$ leads to progressive axonal degeneration in vitro (Ctrl: $0.898 \pm 0.014$ integrity index; Mdivi: $0.764 \pm 0.031$ integrity index, $p=0.0491$; Fig. $5 B$ ). This is consistent with the physiological role of mitochondrial fission in cellular homeostasis, which might explain the partial protection conferred by Mdivi treatment in injured axons. These results strongly suggest that both necroptosis and mitochondria fragmentation are involved in axonal degeneration by a cell-autonomous mechanism and triggered by diverse prodegenerative insults.

\section{The downstream effector of necroptosis MLKL is transiently} activated after axonal damage

To evaluate the capability of embryonic DRG cultures to activate necroptosis, DRG explants were exposed to TNF $\alpha(100 \mathrm{ng} / \mathrm{ml})$ and the pan-caspase inhibitor $\mathrm{z}$-Val-Ala-Asp(Ome)-fluoromethylketone $(\mathrm{z}-\mathrm{VAD} ; 20 \mu \mathrm{M})$, which in combination are known to induce necroptosis in diverse cell types (Holler et al., 2000; Degterev et al., 2005). After $72 \mathrm{~h}$ of incubation, only axons were removed and immediately lysed to evaluate the axonal protein levels of key participants of necroptosis by Western blot. All markers, including RIPK3, MLKL, and their phosphorylated forms, increased after treatment with TNF $\alpha / \mathrm{z}-\mathrm{VAD}$. Interestingly, the phosphorylated form of the downstream effector MLKL was significantly increased after $\mathrm{TNF} \alpha / \mathrm{z}-\mathrm{VAD}$ treatment compared with control axons (Ctrl: $1.0003 \pm 0.022 \mathrm{p}$-MLKL fold induction; TNF $\alpha / \mathrm{z}-\mathrm{VAD}: 5.3180 \pm 1.148 \mathrm{p}$-MLKL fold induction, $F_{(3,16)}=3.242, p=0.0006$, ANOVA; Fig. $\left.6 A\right)$. To determine whether necroptosis is activated during axonal degeneration, DRG explants were damaged by axotomy and the axonal levels of p-MLKL were measured. A significant and transient increase of p-MLKL was observed $3 \mathrm{~h}$ after axotomy (Ctrl: $1.00 \pm 0.194$ p-MLKL fold induction; $3 \mathrm{~h}$ veh: $2.390 \pm 0.546 \mathrm{p}$-MLKL fold induction, $p=0.0208$ ), an effect that was significantly inhibited by Nec- 1 treatment ( $3 \mathrm{~h}$ veh: $2.390 \pm 0.546 \mathrm{p}$-MLKL fold induction; $3 \mathrm{~h} \mathrm{Nec}-1: 1.044 \pm 0.094 \mathrm{p}-\mathrm{MLKL}$ fold induction, $F_{(7,28)}=$ $3.307, p=0.0276$, ANOVA; Fig. $6 B$ ). Since necroptosis regulators are poorly expressed in the nervous system, we evaluated the specificity and sensitivity of the pMLKL antibody by using lentivirus expressing shRNA sequences designed against $M L K L$ in axons $3 \mathrm{~h}$ after axotomy, a condition that we already showed to 
A
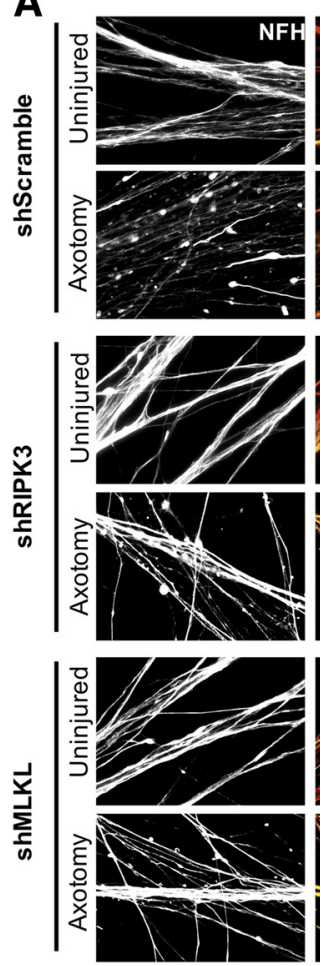
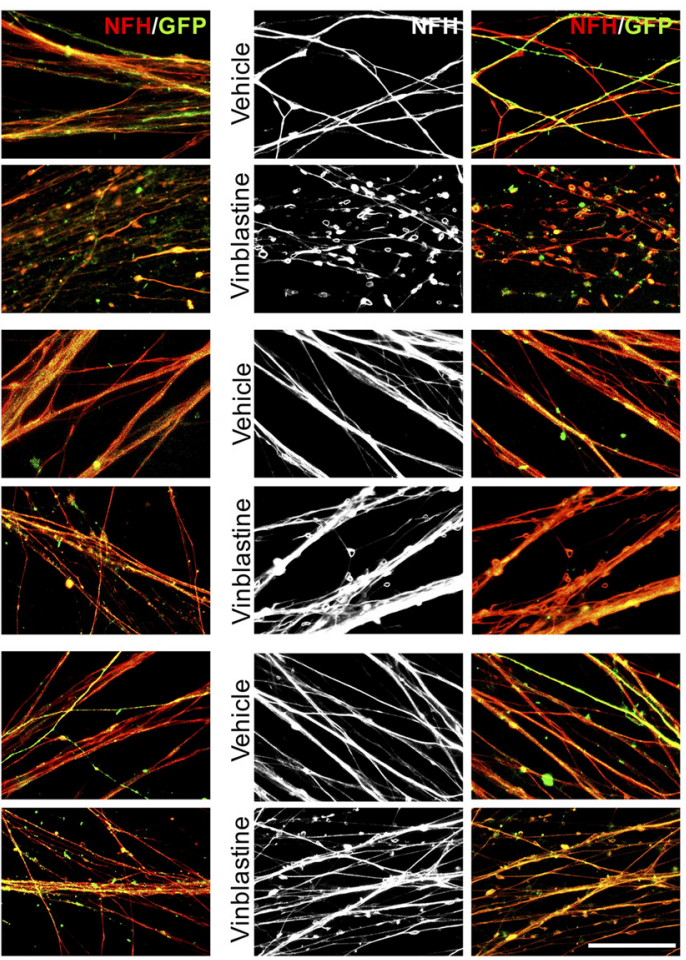
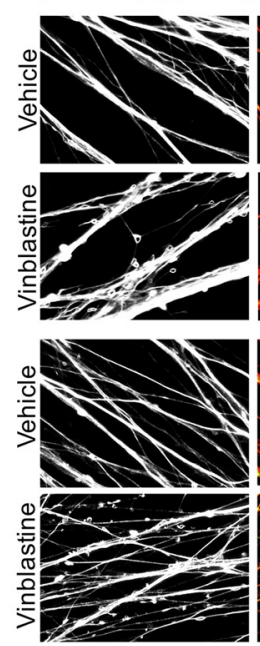

B

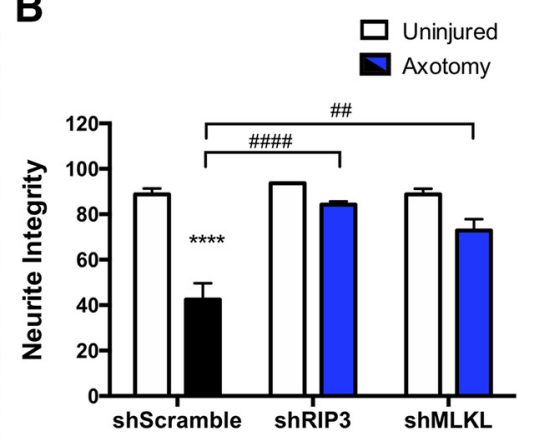

C
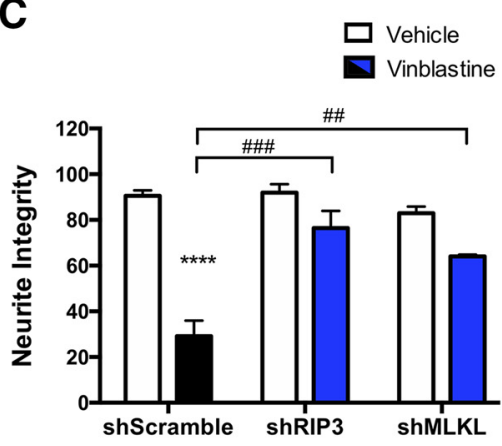

Figure 7. Knock down of RIPK3 and $M L K L$ in sensory neurons protects them from axonal degeneration in vitro. DRGs were transduced with lentiviral vectors containing RIPK3 or MLKL shRNA versus a control nontargeting shRNA (scramble). All plasmids express GFP for identification of transduced neurons. $A$, Representative images before and after injury (axotomy or vinblastine) are shown (NFH in red, GFP signal in green). Scale bar, $5 \mu \mathrm{m}$. B, C, Quantifications of axonal degeneration $8 \mathrm{~h}$ after axotomy $(\boldsymbol{B})$ or $16 \mathrm{~h}$ after vinblastine $(1 \mu \mathrm{m})$ treatment $(\boldsymbol{C})$. Protection with shRIPK3 or shMLKL is represented with blue bars under both conditions. Two-way ANOVA with post hoc Tukey, ${ }^{*}$ indicates statistically significant compared with Veh; \# indicates statistically significant protection compared with axotomized or vinblastine-treated axons.

increase p-MLKL levels (Fig. 6B). A significant decrease in pMLKL was found in shMLKL transduced and injured axons [shScramble (shScr) axotomy: $2.203 \pm 0.105$ p-MLKL fold induction; shMLKL axotomy: $1.425 \pm 0.240 \mathrm{p}-\mathrm{MLKL}$ fold induction, $F_{(1,8)}=9.743, p=0.0297$, ANOVA; Fig. $\left.6 C\right]$. These results indicate that necroptosis is induced in embryonic DRG axons after mechanical injury and that necroptotic regulator levels can be specifically detected by Western blot. Furthermore, to evaluate the magnitude of the knock down, MLKL and RIPK3 mRNA levels were studied by real-time PCR in dissociated DRGs transduced with lentiviral vectors containing shMLKL or shRIPK3 sequences. shMLKL produced a $60 \%$ decrease in MLKL mRNA levels compared with shScramble (shScr: $1.000 \pm 0.00$ p-MLKL fold induction; shMLKL: $0.3935 \pm 0.084 \mathrm{p}$-MLKL fold induction, $F_{(2,9)}=9.056, p=0.0070$, ANOVA), while RIPK3 levels showed nonsignificant changes after MLKL shRNA. shRNA against RIPK3 showed a 36\% fall in RIPK3 mRNA levels (shScr: $1.000 \pm 0.00$ p-MLKL fold induction; shRIPK3: $0.6393 \pm 0.114$ p-MLKL fold induction, $F_{(2,9)}=4.647, p=0.0411$, ANOVA), while MLKL levels were not significantly affected (Fig. 6D).

\section{RIPK3 and MLKL knock down delays axonal degeneration} To evaluate the participation of downstream effectors of necroptosis in injury-induced axonal degeneration at a genetic level, DRG neurons were transduced with lentivirus expressing shRNA sequences designed against RIPK3 and MLKL, or with a scramble sequence as a control. The lentiviral vector coexpresses GFP as a reporter gene to identify transduced neurons in the culture for the subsequent morphological analysis. After transduction, axons were injured by axotomy or chemically damaged with vinblastine. Integrity was evaluated 8 or $16 \mathrm{~h}$ after injury, respectively, by NFH immunostaining in GFP-expressing axons. In neurons transduced with the control shRNA, both injury paradigms induce a massive degeneration of axons (shScr uninjured: $88.787 \pm 2.610 \%$ of integrity; shScr axotomy: $42.491 \pm 7.191 \%$ of integrity, $p<0.0001, F_{(1,12)}=55.47$, two-way ANOVA; shScr veh: 12 h veh: $90.568 \pm 2.342 \%$ of integrity; shScr vinblastine: $29.147 \pm 6.838 \%$ of integrity, $p<0.0001, F_{(1,12)}=69.67$, twoway ANOVA; Fig. 7). In contrast, shRNA for RIPK3 and MLKL effectively protects from axonal degeneration triggered by axotomy or vinblastine treatment (axotomy: shScr: $42.491 \pm 7.191 \%$ of integrity; shRIP3: $84.251 \pm 1.386 \%$ of integrity; or shMLKL: $72.808 \pm 5.057 \%$ of integrity, $p<0.0001$ and $p=0.0016$, respectively, $F_{(2,12)}=18.15$, two-way ANOVA; vinblastine: shScr: $29.147 \pm 6.838 \%$ of integrity; shRIP3: $76.436 \pm 7.520 \%$ of integrity; or shMLKL: $64.097 \pm 0.793 \%$ of integrity, $p=0.0001$ and $p=0.0021$, respectively, $F_{(2,12)}=13.56$, two-way ANOVA; Fig. $7 A, B)$. Together, these results demonstrate that key players of the necroptotic pathway, namely RIPK1, RIPK3, and MLKL, are required for the degeneration of axons triggered by diverse degenerative stimuli and in a cell-autonomous manner.

\section{Discussion}

Axonal degeneration is an active self-destruction program that shares morphological and mechanistic features with necroptosis (Barrientos et al., 2011; Calixto et al., 2012; Villegas et al., 2014; Wallach et al., 2016). Here, we demonstrated that RIPK1 inhibition with Nec-1 protects PNS as well as CNS axons from injuryinduced degeneration, suggesting that necroptosis is a common degenerative program. Nec-1 has the potential to inhibit other 
proteins, such as indoleamine-pyrrole 2,3-dioxygenase, p21 activated kinase-1, and protein kinase A (Cho et al., 2011; Eswaran et al., 2012; Takahashi et al., 2012; Vandenabeele et al., 2013), or to cause inactivation of other cell-death pathways, such as ferroptosis (Conrad et al., 2016). However, we showed by genetic interference of necroptosis activation and execution, through RIPK3 and MLKL knock down, respectively, delayed axonal degeneration in a cell-autonomous fashion, supporting our pharmacological results with $\mathrm{Nec}-1$.

The progression of degeneration was associated with an early activation of necroptosis in axons, followed by mitochondrial fragmentation, which was also prevented by RIPK1 inhibition, indicating that necroptosis activation is triggered upstream of mitochondrial defects after axonal damage. Actually, inhibition of mitochondrial fission delayed axonal degeneration with the same protective magnitude as necroptosis inhibition, suggesting that both events converge in the same cascade for axonal degeneration.

\section{Necroptosis is associated to axonal loss and functional impairment}

Neurons contain at least two molecularly distinct cell-death programs, one for caspase-dependent apoptosis and another for selective axon degeneration. The last one does nor require caspases (Finn et al., 2000; Wang JT et al., 2012).

The molecular mediators of necroptosis, RIPK1, RIPK3, and MLKL, regulate neuronal cell death for several diseases, including ALS (Re et al., 2014; Ito et al., 2016), multiple sclerosis (DhibJalbut and Kalvakolanu, 2015; Ofengeim et al., 2015), AD, and PD (Caccamo et al., 2017; Iannielli et al., 2018). However, to date there is no direct and functional evidence that points out necroptosis as the main program controlling axonal self-destruction.

Many neuropathies are preceded by axonal degeneration, beginning at the distal ends of diseased axons, spreading retrogradely to the soma to trigger neuronal death (Cavanagh, 1979; Coleman, 2005). This suggests that neuronal viability depends on axonal integrity, which makes axons important targets for attenuating disease progression. In fact, inhibition of axonal degeneration protects from cell death and disease progression in several disorders (Ferri et al., 2003; Dadon-Nachum et al., 2011; Yang et al., 2017). This observation is quite relevant considering our results identifying necroptosis as a triggering factor for axonal degeneration by an autonomous-cell mechanism that specifically occurs within the axon. Our results are based on models of Wallerian degeneration; therefore, it will be important to determine whether necroptosis is involved in other non-Wallerian processes of axonal degeneration.

Necroptosis, originally described as a proinflammatory signaling pathway (Silke et al., 2015), occurs in many diseases. CNS diseases are no exception. It has been recently stablished that RIPK1 and RIPK3 are critical mediators of axonal degeneration in ALS by promoting inflammation and necroptosis activation in microglia (Ito et al., 2016). Similarly, necroptosis is required for astrocyte-triggered degeneration and death of motor neurons (Re et al., 2014; Fan et al., 2016). This evidence supports the role of necroptosis under neurodegenerative conditions. Our results showed that after injury, necroptosis is intrinsically activated within axons to trigger axonal degeneration.

RIPK3 is a key component for necrosome formation to trigger necroptosis (Newton et al., 2014; Orozco et al., 2014; Wu et al., 2014). Ablation of RIPK3 in Fadd or capase-8-deficient mice rescues embryonic lethality (Kaiser et al., 2011) particularly by suppressing necroptosis during embryogenesis (Zhao et al., 2017).
Our RIPK3 knock-down studies propose necroptosis as a common pathway required for developmental processes under physiological conditions, but also for axonal destruction after injury or toxic insults. MLKL, the RIPK3 downstream effector (Sun et al., 2012), is responsible for the necrotic plasma membrane disruption, but also can translocate to other compartments as mitochondria (H. Wang et al., 2014), where it could modify oxidative phosphorylation to increase ROS levels (Zhao et al., 2012), events that also occur during axonal degeneration (Calixto et al., 2012). These antecedents point out necroptosis activation in convergence with mitochondrial dysfunction as potential triggering mechanisms of axonal degeneration.

\section{Necroptosis links mitochondrial fragmentation to axonal degeneration}

Mitochondria are considered central sensors for degenerative stimuli (Court and Coleman, 2012). After axonal injury, mitochondrial defects, such as mitochondrial potential loss and swelling, precede axonal fragmentation, making axons more vulnerable (Sievers et al., 2003; Barrientos et al., 2011; Park et al., 2013). Altered mitochondrial dynamics have also been related to pathogenesis of several neurodegenerative conditions (Knott et al., 2008; Grohm et al., 2012; Itoh et al., 2013). Inhibition of the main fission regulator, Drp1 (Smirnova et al., 2001; Otera and Mihara, 2011), delayed axonal degeneration. However, protection is assured. Since Drp1 also modulates mitochondrial function (Grohm et al., 2012), mitochondrial shortening might reflect a progressive organelle dysfunction that could lead to energetic failures and loss of axonal integrity. Conversely, the physiological role of Drp1 in neuronal function should be considered. Drp1 is essential for synapse formation (Ishihara et al., 2009) and for neuronal differentiation and migration (L. Wang et al., 2014), processes in which Drp1 inhibition also affects mitochondrial membrane potential (Kim et al., 2015). These antecedents could explain why axons are not fully protected from degeneration under Drp1 inhibition, and indeed confirm that regulation of mitochondrial fragmentation is a key step in the degenerative process.

Mitochondria-associated membranes (MAMs) constitute the contact sites between the endoplasmic reticulum and mitochondria during fission (Friedman et al., 2011) and have been proposed to contribute to mitochondrial dysfunction during axonal degeneration (Villegas et al., 2014). Interestingly, the active necrosome can translocate to MAMs, where necroptosis could be initiated (Chen et al., 2013). Consistently, the phosphatase PGAM5, a key regulator of Drp1, has been identified as a novel necrosome component (Wang $\mathrm{Z}$ et al., 2012). Our results indicate that necroptosis could mediate axonal degeneration by inducing mitochondrial reshaping. In fact, Drp1 and RIPK1 inhibition reached similar magnitudes of axonal protection, suggesting that they belong on the same pathway on which necroptosis is first activated to then induce mitochondrial fragmentation and axonal degeneration. This observation is sustained by results showing delayed mitochondrial fragmentation under RIPK1 inhibition, strengthening the idea that mitochondrial fission is a convergent point between programmed necrosis and axonal death. According to our results, loss of RIPK3 can rescue Drp1-knockout Purkinje neurons from degeneration, modulating mitochondrial morphology from large spheres into elongated tubules (Yamada et al., 2016). Pharmacological studies with Nec-1 have indicated that RIPK1 inhibition improves mitochondrial function after spinal cord injury (Y. Wang et al., 2015). However, genetic approaches like those we took in our work should be attempted to directly determine the mechanism involved in 
necroptosis-mediated degeneration and its connection with mitochondrial reshaping.

The role of mitochondrial fragmentation and MPTP formation in necroptosis has been a subject of debate, especially considering that MLKL can directly permeabilize the plasma membrane leading to cellular damage. More recent evidence demonstrates that the executory mechanisms of necroptosis can be diverse and are highly dependent on cellular type and context. In sepsis-mediated kidney injury, necrosome formation can lead to mitochondrial dysfunction and ROS production by inhibiting mitochondrial complex I and III (Sureshbabu et al., 2018). In other cells types, necroptosis activation can enhance aerobic respiration and ROS production (Yang et al., 2018). As ROS can trigger mitochondrial fragmentation by diverse mechanisms, including Drp-1 activation (Abuarab et al., 2017; Riba et al., 2017), necroptosis-dependent mitochondrial fragmentation could represent an executioner mechanism for axonal degeneration after injury.

The identification of the prodegenerative gene Sarm1 provided evidence indicating Wallerian degeneration as a program driven by a conserved axonal death pathway (Osterloh et al., 2012; Gerdts et al., 2013; Geisler et al., 2016). It has been shown that mitochondrial dysfunction also stimulates a Sarm1-dependent cell-destruction pathway by a caspase-independent mechanism (Summers et al., 2014), suggesting the participation of necroptosis. However, Sarm1 deletion fails to prevent changes in mitochondrial dynamics occurring after axotomy, despite delaying degeneration (Loreto et al., 2015). Thus, researchers still do now not know whether Sarm 1 participates in or interacts with the necrosome to promote axonal death. A recent study showed that Sarm1-Toll-interleuken receptor-1 domain itself has intrinsic nicotinamide-adenine dinucleotide (NAD) ase activity, which was required to promote axonal $\mathrm{NAD}^{+}$depletion and axonal degeneration after injury (Essuman et al., 2017). Moreover, Yang et al., showed that the necrosome can translocate to the mitochondria to activate pyruvate dehydrogenase, increasing ROS generation, which in turn enhances necrosome formation and necroptosis activation (Yang et al., 2018). These antecedents support our evidence showing that mitochondria converge as a central effector in the necroptotic cascade to initiate axon degeneration.

The present results show that necroptosis participates in the execution program of axonal degeneration as a ubiquitous and cell-autonomous mechanism, regulating both PNS and CNS axonal integrity and function. Furthermore, we reveal the participation of mitochondrial fragmentation as a downstream effector of the necroptotic pathway. Further studies are required to determine what are the main downstream effectors of necroptosis and mitochondria, and how they are inter-regulated to trigger axonal degeneration.

\section{References}

Abuarab N, Munsey TS, Jiang LH, Li J, Sivaprasadarao A (2017) High glucose-induced ROS activates TRPM2 to trigger lysosomal membrane permeabilization and $\mathrm{Zn} 2+$-mediated mitochondrial fission. Sci Signal 10:eaal4161.

Adalbert R, Gillingwater TH, Haley JE, Bridge K, Beirowski B, Berek L, Wagner D, Grumme D, Thomson D, Celik A, Addicks K, Ribchester RR, Coleman MP (2005) A rat model of slow Wallerian degeneration (Wld S) with improved preservation of neuromuscular synapses. Eur J Neurosci 21:271-277.

Alcayaga J, Iturriaga R, Varas R, Arroyo J, Zapata P (1998) Selective activation of carotid nerve fibers by acetylcholine applied to the cat petrosal ganglion in vitro. Brain Res 786:47-54.

Barrientos SA, Martinez NW, Yoo S, Jara JS, Zamorano S, Hetz C, Twiss JL,
Alvarez J, Court FA (2011) Axonal degeneration is mediated by the mitochondrial permeability transition pore. J Neurosci 31:966-978.

Benarroch EE (2015) Acquired axonal degeneration and regeneration: recent insights and clinical correlations. Neurology 84:2076-2085.

Bian P, Zheng X, Wei L, Ye C, Fan H, Cai Y, Zhang Y, Zhang F, Jia Z, Lei Y (2017) MLKL mediated necroptosis accelerates JEV-induced neuroinflammation in Mice. Front Microbiol 8:303.

Bradley WG, Lassman LP, Pearce GW, Walton JN (1970) The neuromyopathy of vincristine in man. J Neurol Sci 10:107-131.

Caccamo A, Branca C, Piras IS, Ferreira E, Huentelman MJ, Liang WS, Readhead B, Dudley JT, Spangenberg EE, Green KN, Belfiore R, Winslow W, Oddo S (2017) Necroptosis activation in Alzheimer's disease. Nat Neurosci 20:1236-1246.

Cai Z, Jitkaew S, Zhao J, Chiang HC, Choksi S, Liu J, Ward Y, Wu LG, Liu ZG (2014) Plasma membrane translocation of trimerized MLKL protein is required for TNF-induced necroptosis. Nat Cell Biol 16:55-65.

Calixto A, Jara JS, Court FA (2012) Diapause formation and downregulation of insulin-like signaling via DAF-16/FOXO delays axonal degeneration and neuronal loss. PLoS Genet 8:e1003141.

Cassidy-Stone A, Chipuk JE, Ingerman E, Song C, Yoo C, Kuwana T, Kurth MJ, Shaw JT, Hinshaw JE, Green DR, Nunnari J (2008) Chemical inhibition of the mitochondrial division dynamin reveals its role in Bax/Bakdependent mitochondrial outer membrane permeabilization. Dev Cell 14:193-204.

Catenaccio A, Llavero Hurtado M, Diaz P, Lamont DJ, Wishart TM, Court FA (2017) Molecular analysis of axonal-intrinsic and glial-associated coregulation of axon degeneration. Cell Death Dis 8:e3166.

Cavanagh JB (1979) The "dying back" process. A common denominator in many naturally occurring and toxic neuropathies. Arch Pathol Lab Med 103:659-664

Chen W, Zhou Z, Li L, Zhong CQ, Zheng X, Wu X, Zhang Y, Ma H, Huang D, Li W, Xia Z, Han J (2013) Diverse sequence determinants control human and mouse receptor interacting protein 3 (RIP3) and mixed lineage kinase domain-like (MLKL) interaction in necroptotic signaling. J Biol Chem 288:16247-16261.

Cho Y, McQuade T, Zhang H, Zhang J, Chan FK (2011) RIP1-dependent and independent effects of Necrostatin-1 in necrosis and T cell activation. PLoS One 6:e23209.

Coleman M (2005) Axon degeneration mechanisms: commonality amid diversity. Nat Rev Neurosci 6:889-898.

Coleman MP, Freeman MR (2010) Wallerian degeneration, WldS, and Nmnat. Annu Rev Neurosci 33:245-267.

Conforti L, Gilley J, Coleman MP (2014) Wallerian degeneration: an emerging axon death pathway linking injury and disease. Nat Rev Neurosci 15:394-409.

Conrad M, Angeli JP, Vandenabeele P, Stockwell BR (2016) Regulated necrosis: disease relevance and therapeutic opportunities. Nat Rev Drug Discov 15:348-366.

Court FA, Coleman MP (2012) Mitochondria as a central sensor for axonal degenerative stimuli. Trends Neurosci 35:364-372.

Dadon-Nachum M, Melamed E, Offen D (2011) The "dying-back" phenomenon of motor neurons in ALS. J Mol Neurosci 43:470-477.

Daniels BP, Snyder AG, Olsen TM, Orozco S, Oguin TH 3rd, Tait SWG, Martinez J, Gale M Jr, Loo YM, Oberst A (2017) RIPK3 restricts viral pathogenesis via cell death-independent neuroinflammation. Cell 169: 301-313.e11.

Debanne D, Campanac E, Bialowas A, Carlier E, Alcaraz G (2011) Axon physiology. Physiol Rev 91:555-602.

Degterev A, Huang Z, Boyce M, Li Y, Jagtap P, Mizushima N, Cuny GD, Mitchison TJ, Moskowitz MA, Yuan J (2005) Chemical inhibitor of nonapoptotic cell death with therapeutic potential for ischemic brain injury. Nat Chem Biol 1:112-119.

Degterev A, Hitomi J, Germscheid M, Ch'en IL, Korkina O, Teng X, Abbott D, Cuny GD, Yuan C, Wagner G, Hedrick SM, Gerber SA, Lugovskoy A, Yuan J (2008) Identification of RIP1 kinase as a specific cellular target of necrostatins. Nat Chem Biol 4:313-321.

Dhib-Jalbut S, Kalvakolanu DV (2015) Microglia and necroptosis: The culprits of neuronal cell death in multiple sclerosis. Cytokine 76:583-584.

Di Stefano M, Loreto A, Orsomando G, Mori V, Zamporlini F, Hulse RP, Webster J, Donaldson LF, Gering M, Raffaelli N, Coleman MP, Gilley J, Conforti L (2017) NMN deamidase delays Wallerian degeneration and 
rescues axonal defects caused by NMNAT2 deficiency in vivo. Curr Biol 27:784-794.

Donaldson J, Shi R, Borgens R (2002) Polyethylene glycol rapidly restores physiological functions in damaged sciatic nerves of guinea pigs. Neurosurgery 50:147-156; discussion 156-157.

Essuman K, Summers DW, Sasaki Y, Mao X, DiAntonio A, Milbrandt J (2017) The SARM1 Toll/interleukin-1 receptor domain possesses intrinsic NAD + cleavage activity that promotes pathological axonal degeneration. Neuron 93:1334-1343.e5.

Eswaran J, Li DQ, Shah A, Kumar R (2012) Molecular pathways: targeting p21-activated kinase 1 signaling in cancer: opportunities, challenges, and limitations. Clin Cancer Res 18:3743-3749.

Fan H, Zhang K, Shan L, Kuang F, Chen K, Zhu K, Ma H, Ju G, Wang YZ (2016) Reactive astrocytes undergo M1 microglia/macrophages-induced necroptosis in spinal cord injury. Mol Neurodegener 11:14.

Ferri A, Sanes JR, Coleman MP, Cunningham JM, Kato AC (2003) Inhibiting axon degeneration and synapse loss attenuates apoptosis and disease progression in a mouse model of motoneuron disease. Curr Biol 13: $669-673$.

Finn JT, Weil M, Archer F, Siman R, Srinivasan A, Raff MC (2000) Evidence that Wallerian degeneration and localized axon degeneration induced by local neurotrophin deprivation do not involve caspases. J Neurosci 20 : 1333-1341.

Friedman JR, Lackner LL, West M, DiBenedetto JR, Nunnari J, Voeltz GK (2011) ER tubules mark sites of mitochondrial division. Science 334: $358-362$.

Geden MJ, Deshmukh M (2016) Axon degeneration: Context defines distinct pathways. Curr Opin Neurobiol 39:108-115.

Geisler S, Doan RA, Strickland A, Huang X, Milbrandt J, DiAntonio A (2016) Prevention of vincristine-induced peripheral neuropathy by genetic deletion of SARM1 in mice. Brain 139:3092-3108.

Gerdts J, Summers DW, Sasaki Y, DiAntonio A, Milbrandt J (2013) Sarm1mediated axon degeneration requires both SAM and TIR interactions. J Neurosci 33:13569-13580.

Gerdts J, Summers DW, Milbrandt J, DiAntonio A (2016) Axon self-destruction: new links among SARM1, MAPKs, and NAD+ metabolism. Neuron 89:449-460.

Grohm J, Kim SW, Mamrak U, Tobaben S, Cassidy-Stone A, Nunnari J, Plesnila N, Culmsee C (2012) Inhibition of Drp1 provides neuroprotection in vitro and in vivo. Cell Death Differ 19:1446-1458.

Heermann S, Spittau B, Zajzon K, Schwab MH, Krieglstein K (2012) Schwann cells migrate along axons in the absence of GDNF signaling. BMC Neurosci 13:92.

Holler N, Zaru R, Micheau O, Thome M, Attinger A, Valitutti S, Bodmer JL, Schneider P, Seed B, Tschopp J (2000) Fas triggers an alternative, caspase-8-independent cell death pathway using the kinase RIP as effector molecule. Nat Immunol 1:489-495.

Hoopfer ED, McLaughlin T, Watts RJ, Schuldiner O, O'Leary DD, Luo L (2006) Wlds protection distinguishes axon degeneration following injury from naturally occurring developmental pruning. Neuron 50: 883-895.

Huang JF, Shang L, Zhang MQ, Wang H, Chen D, Tong JB, Huang H, Yan XX, Zeng LP, Xiong K (2013) Differential neuronal expression of receptor interacting protein 3 in rat retina: Involvement in ischemic stress response. BMC Neurosci 14:16.

Iannielli A, Bido S, Folladori L, Segnali A, Cancellieri C, Maresca A, Massimino L, Rubio A, Morabito G, Caporali L, Tagliavini F, Musumeci O, Gregato G, Bezard E, Carelli V, Tiranti V, Broccoli V (2018) Pharmacological inhibition of necroptosis protects from dopaminergic neuronal cell death in Parkinson's disease models. Cell Rep 22:2066-2079.

Ishihara N, Nomura M, Jofuku A, Kato H, Suzuki SO, Masuda K, Otera H, Nakanishi Y, Nonaka I, Goto YI, Taguchi N, Morinaga H, Maeda M, Takayanagi R, Yokota S, Mihara K (2009) Mitochondrial fission factor Drp1 is essential for embryonic development and synapse formation in mice. Nat Cell Biol 11:958-966.

Ito Y, Ofengeim D, Najafov A, Das S, Saberi S, Li Y, Hitomi J, Zhu H, ${ }^{* *}$ Chen H, Mayo L, Geng J, Amin P, DeWitt JP, Mookhtiar AK, Florez M, Ouchida AT, Fan JB, Pasparakis M, Kelliher MA, Ravits J, et al. (2016) RIPK1 mediates axonal degeneration by promoting inflammation and necroptosis in ALS. Science 353:603-608.

Itoh K, Nakamura K, Iijima M, Sesaki H (2013) Mitochondrial dynamics in neurodegeneration. Trends Cell Biol 23:64-71.
Kaiser WJ, Upton JW, Long AB, Livingston-Rosanoff D, Daley-Bauer LP, Hakem R, Caspary T, Mocarski ES (2011) RIP3 mediates the embryonic lethality of caspase-8-deficient mice. Nature 471:368-372.

Kim HJ, Shaker MR, Cho B, Cho HM, Kim H, Kim JY, Sun W (2015) Dynamin-related protein 1 controls the migration and neuronal differentiation of subventricular zone-derived neural progenitor cells. Sci Rep 5:15962.

Knott AB, Perkins G, Schwarzenbacher R, Bossy-Wetzel E (2008) Mitochondrial fragmentation in neurodegeneration. Nat Rev Neurosci 9: 505-518.

Liu T, Zhao DX, Cui H, Chen L, Bao YH, Wang Y, Jiang JY (2016) Therapeutic hypothermia attenuates tissue damage and cytokine expression after traumatic brain injury by inhibiting necroptosis in the rat. Sci Rep 6:24547.

Loreto A, Di Stefano M, Gering M, Conforti L (2015) Wallerian degeneration is executed by an NMN-SARM1-dependent late $\mathrm{Ca}^{2+}$ influx but only modestly influenced by mitochondria. Cell Rep 13:2539-2552.

Mack TGA, Reiner M, Beirowski B, Mi W, Emanuelli M, Wagner D, Thomson D, Gillingwater T, Court F, Conforti L, Fernando FS, Tarlton A, Andressen C, Addicks K, Magni G, Ribchester RR, Perry VH, Coleman MP (2001) Wallerian degeneration of injured axons and synapses is delayed by a Ube4b/Nmnat chimeric gene. Nat Neurosci 4:1199-1206.

Neukomm LJ, Burdett TC, Seeds AM, Hampel S, Coutinho-Budd JC, Farley JE, Wong J, Karadeniz YB, Osterloh JM, Sheehan AE, Freeman MR (2017) Axon death pathways converge on axundead to promote functional and structural axon disassembly. Neuron 95:78-91.e5.

Newton K, Dugger DL, Wickliffe KE, Kapoor N, de Almagro MC, Vucic D, Komuves L, Ferrando RE, French DM, Webster J, Roose-Girma M, Warming S, Dixit VM (2014) Activity of protein kinase RIPK3 determines whether cells die by necroptosis or apoptosis. Science 343 : 1357-1360.

Nomura M, Ueno A, Saga K, Fukuzawa M, Kaneda Y (2014) Accumulation of cytosolic calcium induces necroptotic cell death in human neuroblastoma. Cancer Res 74:1056-1066.

Ofengeim D, Ito Y, Najafov A, Zhang Y, Shan B, DeWitt JP, Ye J, Zhang X, Chang A, Vakifahmetoglu-Norberg H, Geng J, Py B, Zhou W, Amin P, Berlink Lima J, Qi C, Yu Q, Trapp B, Yuan J (2015) Activation of necroptosis in multiple sclerosis. Cell Rep 10:1836-1849.

Orozco S, Oberst A (2017) RIPK3 in cell death and inflammation: The good, the bad, and the ugly. Immunol Rev 277:102-112.

Orozco S, Yatim N, Werner MR, Tran H, Gunja SY, Tait SW, Albert ML, Green DR, Oberst A (2014) RIPK1 both positively and negatively regulates RIPK3 oligomerization and necroptosis. Cell Death Differ 21:15111521.

Osterloh JM, Yang J, Rooney TM, Fox AN, Adalbert R, Powell EH, Sheehan AE, Avery MA, Hackett R, Logan MA, MacDonald JM, Ziegenfuss JS, Milde S, Hou YJ, Nathan C, Ding A, Brown RH Jr, Conforti L, Coleman M, Tessier-Lavigne M, et al. (2012) dSarm/Sarm1 is required for activation of an injury-induced axon death pathway. Science 337:481-484.

Otera H, Mihara K (2011) Discovery of the membrane receptor for mitochondrial fission GTPase Drp1. Small GTPases 2:167-172.

Park JY, Jang SY, Shin YK, Koh H, Suh DJ, Shinji T, Araki T, Park HT (2013) Mitochondrial swelling and microtubule depolymerization are associated with energy depletion in axon degeneration. Neuroscience 238:258-269.

Re DB, Le Verche V, Yu C, Amoroso MW, Politi KA, Phani S, Ikiz B, Hoffmann L, Koolen M, Nagata T, Papadimitriou D, Nagy P, Mitsumoto H, Kariya S, Wichterle H, Henderson CE, Przedborski S (2014) Necroptosis drives motor neuron death in models of both sporadic and familial ALS. Neuron 81:1001-1008.

Riba A, Deres L, Eros K, Szabo A, Magyar K, Sumegi B, Toth K, Halmosi R, Szabados E (2017) Doxycycline protects against ROS-induced mitochondrial fragmentation and ISO-induced heart failure. PLoS One 12: e0175195.

Sievers C, Platt N, Perry VH, Coleman MP, Conforti L (2003) Neurites undergoing Wallerian degeneration show an apoptotic-like process with annexin $\mathrm{V}$ positive staining and loss of mitochondrial membrane potential. Neurosci Res 46:161-169.

Silke J, Rickard JA, Gerlic M (2015) The diverse role of RIP kinases in necroptosis and inflammation. Nat Immunol 16:689-697.

Smirnova E, Griparic L, Shurland DL, van der Bliek AM (2001) Dynaminrelated protein Drp1 is required for mitochondrial division in mammalian cells. Mol Biol Cell 12:2245-2256. 
Spadari S, Focher F, Kuenzle C, Corey EJ, Myers AG, Hardt N, Rebuzzini A, Ciarrocchi G, Pedrali-Noy G (1985) In vivo distribution and activity of aphidicolin on dividing and quiescent cells. Antiviral Res 5:93-101.

Summers DW, DiAntonio XA, Milbrandt J (2014) Mitochondrial dysfunction induces Sarm1-dependent cell death in sensory neurons. J Neurosci 34:9338-9350.

Sun L, Wang X (2014) A new kind of cell suicide: Mechanisms and functions of programmed necrosis. Trends Biochem Sci 39:587-593.

Sun L, Wang H, Wang Z, He S, Chen S, Liao D, Wang L, Yan J, Liu W, Lei X, Wang X (2012) Mixed lineage kinase domain-like protein mediates necrosis signaling downstream of RIP3 kinase. Cell 148:213-227.

Sureshbabu A, Patino E, Ma KC, Laursen K, Finkelsztein EJ, Akchurin O, Muthukumar T, Ryter SW, Gudas L, Choi AMK, Choi ME (2018) RIPK3 promotes sepsis-induced acute kidney injury via mitochondrial dysfunction. JCI Insight 3:98411.

Taillibert S, Le Rhun E, Chamberlain MC (2016) Chemotherapy-related neurotoxicity. Curr Neurol Neurosci Rep 16:81.

Takahashi N, Duprez L, Grootjans S, Cauwels A, Nerinckx W, DuHadaway JB, Goossens V, Roelandt R, Van Hauwermeiren F, Libert C, Declercq W, Callewaert N, Prendergast GC, Degterev A, Yuan J, Vandenabeele P (2012) Necrostatin-1 analogues: Critical issues on the specificity, activity and in vivo use in experimental disease models. Cell Death Dis 3: e437-e437.

Tonnus W, Linkermann A (2017) The in vivo evidence for regulated necrosis. Immunol Rev 277:128-149.

Tummers B, Green DR (2017) Caspase-8: Regulating life and death. Immunol Rev 277:76-89.

Vandenabeele P, Galluzzi L, Vanden Berghe T, Kroemer G (2010) Molecular mechanisms of necroptosis: An ordered cellular explosion. Nat Rev Mol Cell Biol 11:700-714.

Vandenabeele P, Grootjans S, Callewaert N, Takahashi N (2013) Necrostatin-1 blocks both RIPK1 and IDO: Consequences for the study of cell death in experimental disease models. Cell Death Differ 20:185-187.

Vieira M, Fernandes J, Carreto L, Anuncibay-Soto B, Santos M, Han J, Fernández-López A, Duarte CB, Carvalho AL, Santos AE (2014) Ischemic insults induce necroptotic cell death in hippocampal neurons through the up-regulation of endogenous RIP3. Neurobiol Dis 68:26-36.

Villegas R, Martinez NW, Lillo J, Pihan P, Hernandez D, Twiss JL, Court FA (2014) Calcium release from intra-axonal endoplasmic reticulum leads to axon degeneration through mitochondrial dysfunction. J Neurosci 34:7179-7189.

Wallace TL, Johnson EM Jr (1989) Cytosine arabinoside kills postmitotic neurons: Evidence that deoxycytidine may have a role in neuronal survival that is independent of DNA synthesis. J Neurosci 9:115-124.

Wallach D, Kang TB, Dillon CP, Green DR (2016) Programmed necrosis in inflammation: Toward identification of the effector molecules. Science 352:aaf2154.

Waller A (1850) Experiments on the section of the glossopharyngeal and hypoglossal nerves of the frog, and observations of the alterations pro- duced thereby in the structure of their primitive fibres. Philos Trans R Soc Lond 140:423-429.

Wang H, Sun L, Su L, Rizo J, Liu L, Wang LF, Wang FS, Wang X (2014) Mixed lineage kinase domain-like protein MLKL causes necrotic membrane disruption upon phosphorylation by RIP3. Mol Cell 54:133-146.

Wang JT, Medress ZA, Barres BA (2012) Axon degeneration: molecular mechanisms of a self-destruction pathway. J Cell Biol 196:7-18.

Wang L, Ye X, Zhao Q, Zhou Z, Dan J, Zhu Y, Chen Q, Liu L (2014) Drp1 is dispensable for mitochondria biogenesis in induction to pluripotency but required for differentiation of embryonic stem cells. Stem Cells Dev 23:2422-2434.

Wang MS, Fang G, Culver DG, Davis AA, Rich MM, Glass JD (2001) The WldS protein protects against axonal degeneration: A model of gene therapy for peripheral neuropathy. Ann Neurol 50:773-779.

Wang Y, Wang J, Yang H, Zhou J, Feng X, Wang H, Tao Y (2015) Necrostatin-1 mitigates mitochondrial dysfunction post-spinal cord injury. Neuroscience 289:224-232.

Wang Z, Jiang H, Chen S, Du F, Wang X (2012) The mitochondrial phosphatase PGAM5 functions at the convergence point of multiple necrotic death pathways. Cell 148:228-243.

Whitmore AV, Lindsten T, Raff MC, Thompson CB (2003) The proapoptotic proteins bax and bak are not involved in Wallerian degeneration. Cell Death Differ 10:260-261.

Wu XN, Yang ZH, Wang XK, Zhang Y, Wan H, Song Y, Chen X, Shao J, Han J (2014) Distinct roles of RIP1-RIP3 hetero- and RIP3-RIP3 homointeraction in mediating necroptosis. Cell Death Differ 21:1709-1720.

Yamada T, Adachi Y, Fukaya M, Iijima M, Sesaki H (2016) Dynaminrelated protein 1 deficiency leads to receptor-interacting protein kinase 3-mediated necroptotic neurodegeneration. Am J Pathol 186:2798-2802.

Yang SH, Lee DK, Shin J, Lee S, Baek S, Kim J, Jung H, Hah JM, Kim Y (2017) Nec- 1 alleviates cognitive impairment with reduction of $A \beta$ and tau abnormalities in APP/PS1 mice. EMBO Mol Med 9:61-77.

Yang Z, Wang Y, Zhang Y, He X, Zhong CQ, Ni H, Chen X, Liang Y, Wu J, Zhao S, Zhou D, Han J (2018) RIP3 targets pyruvate dehydrogenase complex to increase aerobic respiration in TNF-induced necroptosis. Nat Cell Biol 20:186-197.

Young KW, Piñon LG, Bampton ET, Nicotera P (2010) Different pathways lead to mitochondrial fragmentation during apoptotic and excitotoxic cell death in primary neurons. J Biochem Mol Toxicol 24:335-341.

Zhang Y, Su SS, Zhao S, Yang Z, Zhong CQ, Chen X, Cai Q, Yang ZH, Huang D, Wu R, Han J (2017) RIP1 autophosphorylation is promoted by mitochondrial ROS and is essential for RIP3 recruitment into necrosome. Nat Commun 8:14329.

Zhao J, Jitkaew S, Cai Z, Choksi S, Li Q, Luo J, Liu ZG (2012) Mixed lineage kinase domain-like is a key receptor interacting protein 3 downstream component of TNF-induced necrosis. Proc Natl Acad Sci U S A 109: 5322-5327.

Zhao Q, Yu X, Zhang H, Liu Y, Zhang X, Wu X, Xie Q, Li M, Ying H, Zhang H (2017) RIPK3 mediates necroptosis during embryonic development and postnatal inflammation in fadd-deficient mice. Cell Rep 19:798-808. 